NASA TECHNICAL MEMORANDUM 100549

AVSCOM TECHNICAL MEMORANDUM 88-B-015

\title{
TENSION FATIGUE ANALYSIS AND LIFE PREDICTION FOR COMPOSITE LAMINATES
}

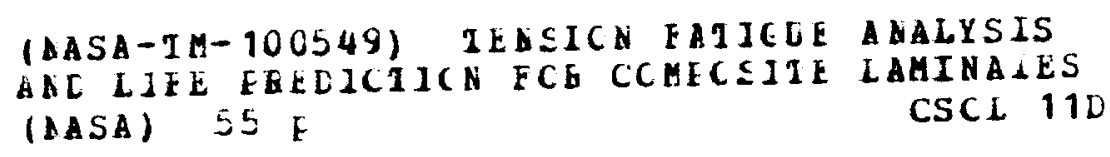

T. K. O'Brien, M. Rigamonti, and $\mathrm{C}$. Zanotti

\section{OCTOBER 1988}
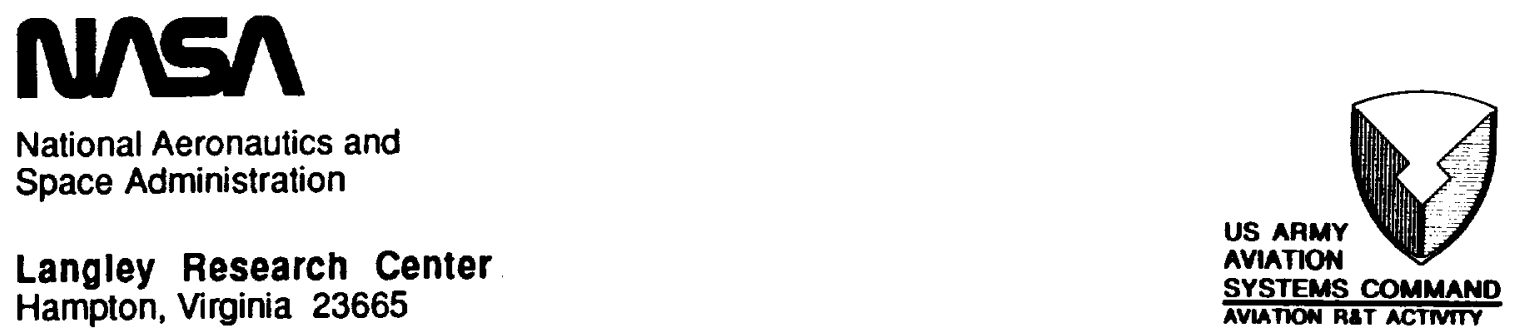


\section{SUMMARY}

A tension fatigue 1 ife prediction methodology for composite laminates is presented. Tension fatigue tests were conducted on quasi-isotropic and orthotropic glass epoxy, graphite epoxy, and glass/graphite epoxy hybrid laminates. Edge delamination onset data were used to generate plots of strain energy release rate as a function of cycles to delamination onset. These plots were then used along with strain energy rolease rate analyses of delaminations initiating at matrix cracks to predict local delamination onset. Stiffness loss was measured experimentally to account for the accumulation of matrix cracks and for delamination growth. Fatigue $f$ ailure was predicted by comparing the increase in global strain resulting from stiffness loss to the decrease in laminate failure strain resulting from delaminations forming at matrix cracks through the laminate thickness. Good agreement between measured and predicted lives indicated that the through-thickness damage accumulation model can accurately describe fatigue failure for laminates where the delamination onset behavior in fatigue is well characterized, and stiffness loss can be monitored in real time to account for damage growth.

Keywords: Composite Materials, Matrix Cracking, Delimination, Fatigue, Stiffness Loss, Strain Energy Release Rate, Fractur. Mechanics 


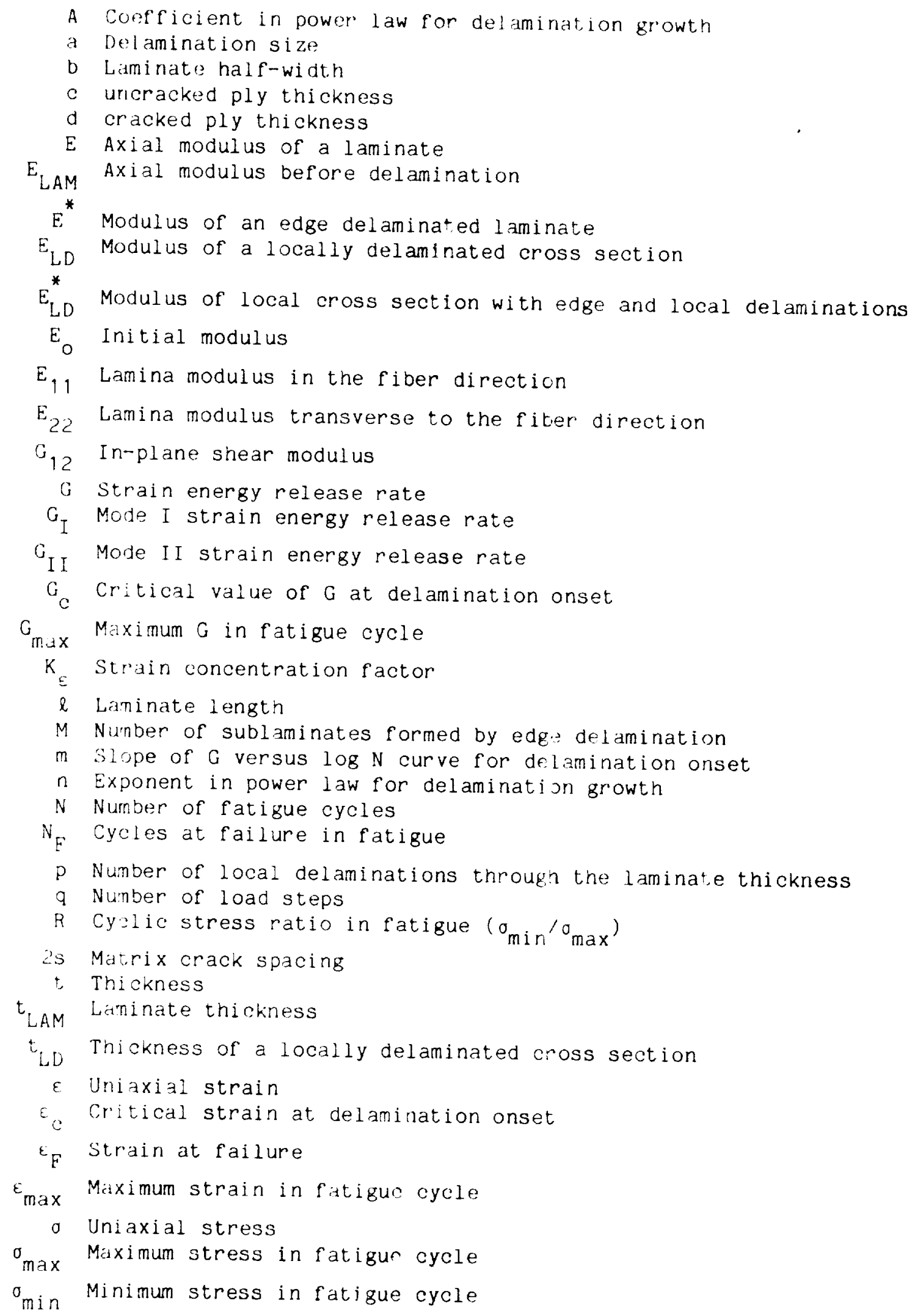




\section{ORIGINAL PAGE IS \\ OF POOR QUALITY}

INTRODUCTION

As composite materials are considered for primary structural applications, the need to predict their fatigue behavior becomes important. For continuous fiber reinforced composites, delamination is the most commonly observed damage mechanism. Fracture mechanics analyses of delaminations have been shown to provide generic characterizations of delamination onset and growtin [1-4]. However, fatigue life prediction requires not only a characterization of delamination behavior, but an assessment of the consequence of $f$ atigue damage as well [3-8]. The purpose of this paper is to develop a fatigue life prediction methodology for composite laminates subjected to tension fatigu+ loading that incorporales both the generic fracture mechanics characterization of delamination as well as the assessment of the influence of damage on laminate fatigue life.

\section{MATERIALS}

Composite laminates were made from pre-impregnated rolls of T190 E-glass fibers embedded in an X751/50 epoxy matrix, and HM35 $\mathrm{graphite} f$ ibers embedded in the same $X 751 / 50$ epoxy matrix. The prepreg material was supplied by cyanamid Fothergill, Ltd., U.K.. Laminates were cured in a press by Agista Helicopter co., Italy, using the manufacturer's recommended curing cycle consisting of a $2.7 \mathrm{~atm}$ pressure and a maximum temperature of $125^{\circ} \mathrm{C}$. Class epoxy, graphite epoxy, and glass/graphite epoxy hybrid laminates were manufactured with an average glass ply thickness of $0.226 \mathrm{~mm}$, graphite ply thickness of $0.1875 \mathrm{~mm}$, and a 48-53\% fiber volume fraction. Specimens $38.1 \mathrm{~mm}$ wide by $300 \mathrm{~mm}$ long were cut from the plates after they were cured and were subsequently tested with a $180 \mathrm{~mm}$ length between the grips of the load frame. Tests were conducted on $[0]_{8}$, [90] 12 , and $[45 /-45]_{4 s}$ glass epoxy and graphite epoxy laminates with similar ply thicknesses and tiber volume fractions to generate the initial lamina property data shown in tables 1-3. Two different batches of T190 E-Glass X751/50 epoxy prepreg were supplied. The first batch was uced to nake the glass epoxy laminates (table 1), and the second batch was used to make the hybrid laminates (table 2). Although the lamina moduli were similar for these two batches, the zero degree failur'; strains were significantly lower for the first batch (tables $1 \& 2)$.

\section{EXPERIMENTS}

Static and tiatigue tests were performed on $(45 /-45 / 0 / 90)$ s quasi-isotropic, glass epoxy and graphite epoxy laminates. In addition, static and fatigue tests were performed on two hybrid laminates. The first was a $(45 /-45 / 0 / 90)_{s}$ quasiisotropic laminate where the $45,-45$, and 0 degree plies had graphite fibers and the 90 degree plies had glass $f i b e r s$ in the same $x 751 / 50$ epoxy matrix. The second was a $(45 /-45 / 0)$ s orthotropic laminate where the 45 and -45 degree plies were graphite and the 0 degree plies wore glass with the same $\times 151 / 50$ epoxy matrix.

Static tension and tension-tension fatigue tests were conducted on an Instron servo-hydraulic test stand. For the static tests, load was applied axially in strok' control. Fatigue tests were conducted in load control by 
applying a sinusoidal load about the mean load at a frequency of $6 \mathrm{~Hz}$ and an $\mathrm{R}-$ ratio of 0.1 . All tests were conducted in an ambient environment with the temperature ranging between $18^{\circ}$ and $25^{\circ} \mathrm{C}$. Axial strain was derived from displacements measured by a pair of Direct Current Differential Transducers (DCDT's) over an 8? mm gage length. Output signals from the loal cell and the DCDT's were plotted on an $X-Y$ recorder. The initial slope of these load displacement plots were used to calculate laminate moduli. During the static tests the machine was stopped at fixed intervals and the damage was recorded. For the glass epoxy laminates, a high intensity light was shone through the specimen to observe and photograph the damage. Because the $\times 751$ epoxy was opaque, a colored dye penetrant was applied to the specimen edges to provide a color-enhanced contrast for viewing the damage. Similarly, a zinc-iodide dye penetrant was used to enhance the X-ray images taken of the graphite epoxy and hybrid laminates for viewing the damage. Matrix crack density and delamination size were measured from high contrast photographic prints. The delaminated area was measured using a graphic tablet to trace the shape of the delamination. This information was transferred to the computer sof tware to calculate the enclosed area.

For each laminate, five quasi-static tension tests were run with a ram speed of $0.5 \mathrm{~mm} / \mathrm{min}$. At specified loads, the specimens were unloaded to record damage and residual stiffness. During the tension-tension fatigue tests, cyclic loading was interrupted at specified intervals to monitor damage and measure static stiffness. To evaluate stiffness, load versus displacement curves were generated by applying a sinusoidal cycle at $0.006 \mathrm{~Hz}$.

\section{STATIC TENSION BEHAVIOR}

For the: quasi-isotropic graphite epoxy laminates, edge delaminations formed in the $0 / 90$ interfaces before final failure of the laminate. Matrix cracks were also visible in the 90 degree plies, however, they had no noticeable effect on the laminate modulus before edge delamination onset. The stress-strain curves were 1 inear up to the onset of edge delamination ( $f$ ig.1).

For the quasi-isotropic glass epoxy laminates, edge delaminations also formed in the $0 / 90$ interfaces before final failure of the laminate. Matrix cracks were also visible in the 90 degree glass plies. However, unlike the graphite epoxy laminates, the stress-strain curves became nonlinear after the onset of 90 degree matrix cracking (fig.1).

For the quasi-isotropic hybrid laminates, static tests showed no edge delamination betore final fracture of the laminate. Matrix cracks were visible in the 90 degree glass plies, however, they had no noticeable effect on the laminate modulus. The stress-strain curves were linear up to the final failure (fig. 2$)$. The final failure stralns for the quasi-isotropic hybrid laminates (table 4! were similar to the failure strains for the high modulus graphite fioers (table 3).

For the orthotropic hybrid laminates, no matrix cracking or delamination was observed in the static tests before final failure of the laminates. However, the stress-3train curves were nonlinear ( $\mathrm{fig} .2$ ). The average failure strain for the orthotropic laminates (table 4) was similar to the failure strain for the Eglass fibers (table 2).

\section{TENSION FATIGUE BEHAVIOR}

Figure 3 show: three dye penetrant enhanced photographs of the tension fatigue damage in the $(45 /-45 / 0 / 90)$ s glass epoxy laminates taken at different 
stages of cyclic loading. These photographs clearly show the edge delaminations and matrix cracks in the 45 degree plies. Local delaminations can also be seen extending from the 45 degree matrix cracks. Figure 4 shows a schematic of some of this damage, including edge delaminations that form at the edge in the $0 / 90$ interface and jump through 90 degree ply cracks to the other $0 / 90$ interface, and local delaminations that form in the 45/-45 interface, originating at 45 degree matrix ply cracks.

The fatigue damage in the glass epoxy laminates progressed in the following sequence. First, extensive matrix cracking developed in the 90 degree plies, followed by edge delamination in the $0 / 90$ interfaces. Next, matrix cracks appeared in the 45 degree and -45 degree plies and initiated local delaminations, first in the $45 /-45$ interfaces, followed by the $-45 / 0$ interfaces. Finally, after enough local delaminations had formed through the thickness at a particular location, flber failure occurred and the laminate failed. The same damage mechanisms, and similar sequences of damage, were observed in the graphite epoxy and hybrid quasi-isotropic laminates. Dye penetrant enhanced radiographs of this damage in T300/5208 graphite epoxy laminates have been documented previously $[6,7]$.

For the glass epoxy laminates, fig.5 shows the number of cycles at a given maximum cyclic stress for edge delaminations to form (solid symbols), for the first local delamination to form at the 45/-45 interface (brackets), and for fatigue failure to occur (open symbols). Fatigue failures occurred in less than $10^{6}$ cycles at maximum stress levels on the order of $50 \%$ of the static strength or greater.

For the graphite epoxy quasi-isotropic laminates, fig. 6 shows the static ultimate strength and the maximum stress versus cycles to onset of edge delamination. Edge delaminations formed in less than $10^{6}$ cycles at maximum stress levels above $50 \%$ of the static strength, but no fatigue failures occurred before $10^{6}$ cycles. Three fatigue tests run at $90 \%$ of the static ultimate stress, where edge delaminations occurred in the first load cycle, also had fatigue lives greater than $10^{6}$ cycles. Although the entire sequence of failure in graphite epoxy laminates has been studied in the past $[6,7]$, for this study only the data up to delamination onset was used for characterization of delamination onset in fatigue.

For the quasi-isotropic, hybrid laminates, fig.7 shows the maximum cyclic stress as a function of cycles to delanination onset and cycles to failure. Although edge delaninations did not form in the hybrid quasi-isotropic laminates under static loading, they did form during cyclic loading at stress levels below the static strengtn of the laminate. Edge delaminations formed in less than $10^{6}$ cycles at maximum stress levels above $50 \%$ of the static strength. However, fatigue failures at less than $10^{6}$ cycles were only observed at maximum stress levels greater than $90 \%$ of the static strength. At these high stress levels, local delaminations also occurred in the 45/-45 interface, growing from matrix cracks in the outermost 45 degree plies. Although these local delaminations were visible on the specimen during testing, they were difficult to document using the dye penetrant enhanced radiography because the small local delaminations were obscured in the radiographs by the image of the $0 / 90$ interface edge delaminations.

For the $(45 /-45 / 0)$ hybrid laminates, fig. 8 shows the maximum cyclic stress as a function of cycles to onset of (1) matrix cracks in the 45 or -45 degree plies, (2) the onset of local delamintion in the 45/-45 degree interface, and 
(3) the final fatigue failure. Fatigue failures occurred in less than $10^{6}$ cycles at maximum stress levels on the order of $50 \%$ of the static strength or greater. These fatigue failures were precipitated by the onset of local delaminations in the $45 /-45$ interface that grew from matrix cracks in the 45 and -45 degree plies. Sections of the failed composite were polished and exarnined in an optical microscope to verify the presence of these damage mechanisms. These sections also showed that local delaminations had formed in the $-45 / 0$ interfaces. These local delaminations were not visible on the radiographs. Furthermore, these polished sections were used to document whether the delamination and matrix cracking was occurring in the matrix or at the fiber matrix interfaces. In the graphite plies, matrix cracks occurred primarily within the matrix, and only occasionaliy at the fiber matrix interface. However, in the glass epoxy laminates, and in the hybrid laminates, the fractographs showed that the delaminations occurred almost exclusively within the glass plies at the fiber matrix interfaces closest to the ply interface (fig.9).

In order to predict the fatigue failure of these laminates, the onset and growth of the damage observed must be characterized, and the influence of this damage on laminate stiffness and strength must be determined. To this end, a fatigue analysis and life prediction methodology.

FATIGUE ANALYSIS AND LIFE PREDICTION METHODOLOGY

Influence of Damage on Laminate Stiffness

Several damage mechanisms may reduce the stiffness of a composite laminate. The most commonly observed fatigue damage mechanisms are matrix cracking and delamination. In this section, the influence of matrix cracking and delamination on laminate stiffness will be reviewed.

Fig.10 shows the influence of damage on laminate stiffness. As matrix cracks accumulate, and as delaminations form and grow, the stiffness of the laminate decreases. Laminate stiffness is the ratio of the remote stress to the global strain in the laminate. This global strain is typically measured using an extensometer or DC!) ( 1 ig.10), which yields the displacement of the laminate over a fairly long gage length relative to the laminate's length. As damage forms and grows in the laminate under a constant maximum cyclic stress, corresponding to a constant applied maximum cyclic load, the global strain in the laminat increases.

Previous studies have determined the relationships between stiffness loss and damage extent $[1-10]$. The amount of stiffness loss associated with matrix cracking depends upon the ply orientation of the cracked ply, the laminate layup, the relative moduli of the $f i b e r$ and the matrix, and the crack spacing, or density of cracks, in the ply. For example, in ref.4, an equat,ion was derived for stiffness loss due to matrix cracking in 90 degree plies of cross ply laminates as

$$
E=\frac{E_{L A M}}{1+(1 / \lambda s)(c / d)\left(E_{22} / E_{11}\right) \tanh (\lambda s)}
$$

where

$$
\lambda=\left\{\frac{3 G_{12}(c+d) E_{\text {LAM }}}{c^{2} d E_{11} E_{22}}\right\}^{1 / 2}
$$




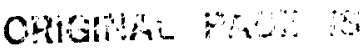

\section{OF. POOR QUALITY}

and $c$ and $d$ are the thickness of the cracked and uncracked plies, respectively. As the crack density increases, i.e., as the crack spacing, 2 , decreases, the stiffness of the laminate will decrease. For a particular layup with a given crack density, the stiffness loss would be larger for glass epoxy than graphite cpoxy because the ratio of the transverse to axial modulus, $E_{22} / E_{11}$, is greater

for glass epoxy than for graphite epoxy (fig.11a). For example, fig. 11 b shows the maximum stiffness loss when matrix cracking has saturated in the 90 degree plies of cross ply laminates made of graphite epoxy and E-glass epoxy. The glass epoxy laminates have significantly greater stiffness loss than the graphite epoxy laminates.

The amount of stiffness loss due to delamination also depends on the laminate layup and the relative modulus of the $f i b e r$ and the matrix, as well as the location and extent of the delamination. As delaminations form and grow in a particular interface, the laminate stiffness decreases as the delamination size, a, Increases. In ref.1, an equation was derived for the stiffness loss associated with edge delamination as

$$
E=\left(E^{*}-E_{L A M}\right) a / b+E_{L A M}
$$

where $a / b$ is the ratio of the delamination size to the laminate half-width, and $E^{*}$ is determined from a rule of mixtures expression

$$
E^{*}=\sum_{i=1}^{M} \frac{E_{i} t_{i}}{t}
$$

where the moduli, $E_{i}$, of the $M$ sublaminates formed by the delamination are calculated from laminated plate theory. The difference in $E_{L A M}$ and $E^{*}$ reflects the loss of transverse constraint in the sublaminates formed by the delamination. The greater the ratio of the transverse to axial lamina moduli, $\mathrm{E}_{22} / \mathrm{E}_{11}$, the lesis the transverse constralnt, resulting in less difference in $E_{L A M}$ and $E^{*}$. For example, fig.12 shows the percentage stiffness loss, as measured by $\left(E_{L A M}-E^{*}\right.$ )/E $E_{L A M}$, for edge delamination in the $0 / 90$ interfaces of $(45 /-45 / 0 / 90)_{S}$ E-glass epoxy, graphite epoxy, and nybrid laminates. As noted earlier, the 8 lass epoxy has the largest ratio of $E_{22} / E_{11}$, and hence has the smallest stiffness loss when delaminated.

Delaminations starting from matrix cracks will effect laminate stiffness differently than delaminations growing from the straight edge. In ref.2, an equation was derived for the stiffness loss associated with delaminations from matrix cracks as

$$
E=\left\{(a / l) t_{L A M}\left[1 /\left(t_{L D} E_{L D}\right)-1 /\left(t_{L A M} E_{L A M}\right)\right]\right\}^{-1}
$$

where $a / \ell$ is the ratio of the delamination length to the laminate length, and $t_{L D}$ and $E_{L D}$ represent the thickness and modulus of the locally delaminated 
region in the vicinity of the matrix crack. Hence, the locally delaminated modulus, $E_{L D}$, is the modulus of the laminate without the cracked plies that

caused the local delamination. This locally delaminated modulus is similar to $E^{*}$ in eq(4). However, in addition to reflecting the loss in transverse constraint due to the delamination, $E_{L D}$ also reflects the loss of the load bearing capacity of the cracked ply. Similar to edge delamination, the st ffriess of the laminate decreases as the size of the delamination increases. However, unlike edge delaminations which form at the two edges and grow prigressively towards the center of the laminate width, local delaminations tend to accumulate at several matrix cracks along the length, growing only a smal distance at any one location. The cumulative effect of these local delam nations with cycles, however, may have a significant effect on measured stiffniss loss.

Delamination Onset and Growth Characterization

In order to predict stiffness loss as a furction of fatigue cycles, the onset and growth of matrix cracks and delaminations mus be characterized in terms of a generic parameter that is representative of the composite material being tested, but independent of laminate structural variables such as layup, stacking sequence, and ply thickness. This characterization is typicaliy achieved using the strain energy release rate, G, associated with matrix cracking and delamination $[1-4,11-17]$.

Fig.13 shows the steps that would be required to predict stiffness loss as a function of fatigue cycles using a $G$ characterization of damage onset and growth. First, plots of $\mathrm{G}$ versus $\mathrm{log} \mathrm{N}$ must be generated to characterize the onset of delamination $[3,12-16]$, and power 1 aw relationships between $G$ and the rate of growth of delamination with fatigue cycles are needed to characterize damage growth $[11,15]$ (fig.13a). Similar approaches may be used to characterize the onset and growth of matrix cracks [4]. Using these material characterizations, the decrease in matrix crack spacing, $2 s$, and the increase in delamination size, a, with fatigue cycles may be predicted (fig.13b). This information, in turn, may be used with eqs (1-5) to predict the decrease in modulus with cycles, which for a constant stress amplitud" test is tantamount to predicting the increase in global strain with cycles (fig.13c).

Although this technique may be demonstrated for cases where there is one dominant damage mechanism, application of this approach in general is difficult because the various damage modes interact, complicating their unique characterization in terms of $G$ [4]. For example, although the elastic analysis for $G$ associated with edge delamination growth is independent of delamination size, stable delamination growth is of ten observed experimentally $[1,6,17]$. The strain energy release rate for edge delamination is given by

$$
G=\frac{\varepsilon^{2} t_{L A M}}{2}\left(E_{L A M}-E^{*}\right)
$$

which is independent of the delamination size. Theoretically, when a critical value of strain, $\varepsilon_{c}$, is reached, corresponding to a critical $G_{c}$, the delamination should form on the edge and grow immediately through the width. However, edge delaminations usually grow in a stable fashion, requiring increasing strain levels, and hence increasing $G$, for the delamination to grow across the width. This stable growth may be correlated with the accunulation of 90 degree matrix cracks ahead of the delamination front. For example, fig. 14 
shows a plot of normalized delamination size, a/b, as a function of the strain applied to an eleven-ply $( \pm 30 / \pm 30 / 90 / \overline{90})_{s}$ T300/5208 graphite epoxy laminate. The edge delaminations form at a strain of approximately 0.0035 , but do not grow across the specimen width until the strain reaches approximately 0.0065 . Also plotted in fig. 14 on the right hand ordinate is the 90 degree ply crack spacing measured in the center of the laminate. There appears to be a direct correlation between the stable delamination growth and the accumulation of matrix cracks ahead of the delamination front. These matrix cracks apparently interact with the delamination and increase the resistance to delamination growth. Stable delamination growth may be predicted by generating a delamination resistance $R-$ curve using eq.6 [1,17]. However, the resulting R-curve is no longer generic, because the matrix cracking that is causing the delamination resistance is governed by structural variables such as ply thickness and stacking sequence.

Delamination also influences the formation and accumulation of matrix cracks. Delamination relaxes the constraint of neighboring plies, and hence changes the saturation spacing of matrix cracks in the of f-axis plies. For example, when delaminations form at the edges of the $( \pm 30 / \pm 30 / 90 / \overline{90})_{s}$ laminate shown in fig.6, the constralnt between the $-30 \mathrm{deg}$ and 90 deg plies is relaxed, and the $90 \mathrm{deg}$ cracks form sooner, with smaller crack spacings than possible if no delamination had existed [1]. An R-curve description of matrix cracking has been used to describe the accumulation of matrix cracks, similar to the approach that has been attempted for delamination [4]. However, when these cracks interact with delaminations, this description is no longer generic.

Even if one could achieve a truly generic description of damage accumulation with cycles, the resulting stiffness loss prediction, and hence the prediction of increasing global strain with cycles, is necessary, but not sufficient, to predict fatigue life. The final failure of the laminate is governed not only by loss in stiffness, but also by the the local strain concentrations that develop in the primary load bearing plies, which in most laminates are zero degree plies.

Influence of Local Strain Concentrations on Failure

Fig.15a shows that fatigue failures typically occur after the global strain has increased because of the fatigue damage growth, but before this global strain reaches the global strain at failure, $\varepsilon_{F}$, measured during a static strength test $[5-8]$. Therefore, local strain concentrations must be present in the zero degree $\mathrm{pli}$ ies that control the laminate strength. Although matrix cracks create small strain concentrations in the neighboring plies, their magnitudes are generally small because the stiffness of the cracked ply is usually much less than the stiftness of the zero degree ply [8]. Furthermore, strain concentrations due to matrix cracks act over only a local volume near the crack tip in the adjacent ply [8]. Hence, the final failure in a zero degree ply of a laminate may follow a neighboring ply crack [18], but the laminate failure strain will not be strongly influenced by the presence of the matrix cracking [8]. Once delaminations initiate at matrix ply cracks, however, the local strain w1ll increase significantly throughout the remaining through-thickness cross section [2,5-8]. These local strain increases may not be sensed by the global strain measurement, because delaminations starting from matrix cracks grow very little once they form. If several delaminations form at matrix cracks throughout the laminate thickness at one location, then the local strain on the zero degree plies at that location may reach the static failure strain, resulting in the observed fatigue failure ( $f$ ig.15b). 
This mechanism for fatigue failure has been observed previously for graphite epoxy laminates [3,5-8], and the local strain concentrations resulting from cumulative local delaminations through the thickness have been quantified $[2,3,5-8]$. These local strain concentrations may be calculated as

$$
K_{\varepsilon}=\frac{E_{L A M} t_{L A M}}{E_{L D} t_{L D}}
$$

Typically, the local strain concentration will result in a trade of $f$ between the increased modulus, $E_{L D}>E_{L A M}$, which occurs because $E_{L D}$ is a more zero degree dominated layup than the original laminate, and the decrease in load bearing cross section, $t_{L D}<t_{L A M}$. Fig. 16 shows the local strain concentrations calculated for local delaminations accumulating through the thickness in a $(45 /-45 / 0)_{s}$ E-glass epoxy laminate. For each progressive delamination that forms through the thickness, the local strain concentration on the zero degree plies increases.

In some cases, these local delaminations will be influenced by other mechanisms. For example, if the local delamination forms at an edge, where an edge delamination exists in another interface (fig.17), the local strain concentration in the zero degree plies near the edge will be

$$
K_{\varepsilon}^{*}=\frac{E^{*} t_{L A M}}{E_{L D}^{*} t_{L D}}
$$

instead of $K_{\varepsilon}$ calculated from eq.7, which is valid away from the edge delamination in the interior of the laminate width. Fig.18 shows values of $k_{E}$ and $K_{\varepsilon}^{*}$ for through-the-thickness accumulation of local delaminations in $(45 /-45 / 0 / 90)_{s}$ E-glass epoxy laminates containing delaminations near the edges in the $0 / 90$ interfaces. For a given through-thickness accumulation of local delaminations, $K_{\varepsilon}^{*}<K_{\varepsilon}$, because $E^{*} / E_{L D}^{*}<E_{L A M} / E_{L D}$. In fig.19, $K_{E}^{*}$ values are plotted for the same quasi-isotropic laminate using both E-glass epoxy and graphite epoxy properties. As shown in $\mathrm{fig} .19$, for the same layup and damage situation, the resulting local strain concentration will be more severe for the E-glass epoxy than for the graphite epoxy laminate.

As noted earlier, each time a local delamination initiates from a matrix crack, the loctl strin in the the remaining through thickness cross section, and hence in the zero tegree plies, increases by an amount equal to $k_{E} t i m e s$ the global cyclic strain, $\varepsilon_{\max }$, until the local strain reaches the static failure strdin, $\varepsilon_{F}$ (fig.20a). A simpler way to visualize this process however, is to reduce the static failure strain to some effective global $\varepsilon_{F}$ value each time a new local delamination forms through the thickness. Hence, the effective failure strain for the "i"th delamination, $\left(\varepsilon_{F}\right)_{i}$, would be equal to $\varepsilon_{F} /\left(k_{\varepsilon}\right)_{i}$. As local delaminations accumulated through the thickness, $\left(\varepsilon_{F}\right)_{i}$ would decrease incrementally. Fatigue failure would correspond to the number of cycles where 


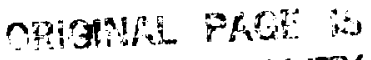 \\ OF POOR QUALTYY}

the damage growth increased the global maximum cyclic strain to the current value of $\left(\varepsilon_{F}\right)_{i}$ (fig.?0b). This approach does not require a prediction of damage growth with fatigue cycles if the laminate stiffness loss, and hence the increase in global strain, can be monitored in real time. When this is possible, only the incremental decreases in $\left(\varepsilon_{F}\right)_{i}$ needs to be predicted to predict fatigue life. This may be accomplished by first assuming that matrix cracks exist in all of the off-axis plies. Then, the number of fatigue cycles to onset of each local delamination through the thickness may be predicted using delamination onset criteria ( $f$ ig.13a) along with strain energy release rate analyses for local delamination. At a given location, as each local delamination forms through the thickness, $\varepsilon_{F}$ may be reduced by the appropriate $K_{\varepsilon}$ and compared to the current value of $\varepsilon_{\max }$, based on measured stiffness loss, to determine if fatigue failure will occur. Hence, the ability to predict local delamination onset, and its effect on $\varepsilon_{F}$, facilitates using measured stiffness loss to predict fatigue life.

\section{Tension Fatigue Life Prediction Procedure}

In order to predict the onset of local delaminations with fatigue cycles, the $G$ versus $\log N$ characterization of the composite material must be generated. Data from several materials with brittle and tough matrices indicate that between $10^{0} \leqq N \leqq 10^{6}$ cycles, the maximum cyclic G may be represented as a linear function of $\log \mathrm{N}$ ( $\mathrm{fig} .21$ ), where $\mathrm{N}$ is the number of cycles to delamination onset at a prescribed $G_{\max }[13]$. Hence,

$$
G=m \log N+G_{C}
$$

where $G_{c}$ and $m$ are material parameters that characterize the onset of delamination under static and cyclic loading in the material (fig.13a). This characterization may be accomplished using a variety of interlaminar fracture test methods $[12 \cdot 16]$. Next, $G$ must be calculated for each local delamination as it accumulates through the thickness. The first local delamination will typically form at a matrix crark in the surface ply, but the appropriate sequence inay be confirmed by calculating $G$ for matrix cracking in all of the of $f-a x$ is plies in the laminate. The one with the highest $G$ for the same applied load will be the first to form. This G may be calculated using the equation derived in ref'. for the strain energy release rate associated with local delamination:; initiating at matrix cracks

$$
G=\frac{0^{2} t_{L A M}^{2}}{2}\left[1 /\left(t_{L D} E_{L D}\right)-1 /\left(t_{L A M} E_{L A M}\right)\right]
$$

As shown in fig. 22, the thickness and modulus terms in eq(10) change for each succesive local delamination that forms through the thickness. For example, $t_{L D}$ and $E_{L D}$ for a $45 /-45$ local delamination in a $(45 /-45 / 0) \mathrm{s}$ laminate becomes the $t_{L A M}$ and $E_{L A M}$ values used to calculate $G$ for the next local delamination that forms through the thickness. Therefore, under a constant $\sigma_{\max }$ as local delaminations accumulate through the thickness, the driving force (i.e., G) for 
each new delamination changes. Hence, fatigue life prediction for composite laminates requires a "cumulative damage" calculation, even for constant amplitude loading. To calculate the number of cycles for each succesive local delamination to form, $\mathrm{N}_{\mathrm{i}}$, the appropriate expression for $\mathrm{G}$ from eq(10) is set equal to the delamination onset criterion of eq(9) (fig.22) and the equation is solved for $\mathrm{N}_{\mathrm{i}}(\mathrm{fig} .23)$. Hence,

$$
\log N_{i}=\frac{1}{m}\left\{\frac{\sigma_{\max }^{2}}{2}\left(t_{L A M}^{2}\right)_{i}\left[1 /\left(t_{L D} E_{L D}\right)-1 /\left(t_{L A M} E_{L A M}\right)\right]_{i}-G_{0}\right\}
$$

and the effective $\left(\varepsilon_{F}\right)_{i}=\varepsilon_{F} /\left(K_{E}\right)_{i}$.

Fatigue failure will occur when $\varepsilon_{\max } \geq\left(\varepsilon_{F}\right)_{i}$, resulting in a fatigue life, $N_{F}$, of

$$
N_{F}=\sum_{i=1}^{p} N_{i}
$$

where $p$ is the number of local delaminations that form through the thickness of the laminate before failure.

Because of the scatter in experimental data, the constant load amplitude fatigue 1 ife prediction methodology outlined in $f i g .23$ more closely resembles $\mathrm{fig} .24$. The variation in initial laminate modulus (i.e., the variation in $\varepsilon_{\max }$ ) and the variations in static failure strains from specimen to specimen must be taken into account. Hence, a range of possible fatigue lives would be predicted, rather than a single value. The lowest life would occur when then minimum value of $\left(E_{F}\right)_{i}$ in the $\varepsilon_{F}$ distribution reaches the largest $\varepsilon_{\text {max }}$ value in the distribution resulting from variations in laminate moduli.

RESULTS

Fatigue Delamination Characterization

The fatigue life methodology outlined in the previous sections was used to predict the fatigue life of the quasi-isotropic glass epoxy laminates and the quasi-isotropic and orthotropic hybrid laminates. To make these predictions, the delamination onset behavior in fatiguc for these materials was first characterized in terms of strain energy release rates.

For the glass epoxy quasi-isotropic laminates, the lamina properties used to calculate $E_{L A M}$ and $E^{*}$ were reduced to reflect the stiffness loss that preceeded edge delamination onset. Specifically, $E_{22}$ was reduced by $29 \%$ based on a shear 1 ag analysis $[1,9]$ to reflect the saturation cracking in the 90 deg plies. However, this reduction in $\mathrm{E}_{22}$ of the 90 degree plies, when substituted into the laminated plate theory, yielded laminate moduli that were significantly greater than moduli measured just before edge delamination onset. Because the \pm 45 degree $p l i e s$ were loaded to relatively high strain levels $(>0.01)$ before edge delamination onset, the nonlinearity in the stress-strain curve before edge 
delamination onset was attributed to the matrix dominated response of the \pm 45 degree glass epoxy plies. This nonlinearity is similar to the nonlinearity observed in quasi-static tests of $( \pm 45 / 0)$ s E-glasi X751/50 epoxy laminates which show no evidence of matrix cracking in the \pm 45 degrte plies. Hence, $G_{12}$ in the \pm 45 degree $p l i e s$ was reduced by $50 \%$ to reflect the nonl inearit, observed. These reduced lamina properties (table 1) yielded quasi-isotropic longitudinal moduli, $E_{\text {LAM }}$, calculated by laminated plate theory, that were consistant with $E_{0}$ values measured just before edge delamination onset in the fatigue tests (table 4). In the absence of real time stiffness measurement, the cyclic plasticity of the \pm 45 degree plies would have to be characterized in addition to the characterization of matrix cracking and delamination [19]. However, this would only be necessary in laminates where the zero degree plies were load»d to very high cyclic strain levels without failing, as was the case for the sero degree glass plies in the quasi-isotropic glass epoxy and orthotropic hybrid laminates (table 4).

The maximum cyclic strains for edge delamination onset in the quasiisotropic glass epoxy laminates were used in eq(6) to calculate strain energy release rates, and the data were plotted versus the number of cycles to delamination onset ( $\mathrm{fig} .25$ ). There was significant scitter in the static data for $G_{c}$, possibly due to the interaction that occurred between the edge delamination as it formed, and the $90 \mathrm{deg}$ ply cracks that were extensive before edge delamination onset. However, $G_{c}$ values from edge delamination data may be artificially elevated if extensive 90 deg ply cracking is present in the laminate $[4,12]$. Therefore, the minimum values in fatigue were used in eq(9) to characterize delamination onset and extrapolate an effective static $G_{c}$. All of these data were generated at the $6 \mathrm{~Hz}$ frequency except for the $\mathrm{N}=2$ data point. This data point was determined from a slow sinusoidal loading where the edge delamination formed at the second peak in the wave form. For the E-glass X751/50 epoxy, an effective $G$ value of $90.2 \mathrm{~J} / \mathrm{m}^{2}$ was obtained, and the slope, $m$, was 10.52 .

Because the stress-strain behavior of the graphite epoxy quasi-isotropic laminates was linear up to the onset of edge delamination, the delaminated modulus, E, could be obtained dinectly from the experimental data. Although 90 degree ply cracks form after the onset of edge delamination and will contribute to stiffneiss loss, the influence of these matrix cracks is not large for graphite epoxy laminates (fig. 1 $\mathrm{b}$ ). However, this influence will be reflected in the experimentally determined value for $E^{*}$. Fig.26 shows the loss in stiffness as a function of delamination area for the graphite/epoxy laminates. Data from both the static and fatigue tests were plotted, and were correlated using a linear least squares regression $\mathrm{fit}$. The extrapolation of the linear $\mathrm{fit}$ to total delamination, $a / b=1.0$, yielded the delaminated modulus.

Fig. 27 shows the maximum strain energy release rate as a function of cycles to edge delamination onset for the quasi-isotropic graphite epoxy laminates. As has been prevously noted $[6,7,12], 90$ degree ply cracking is not extensive in $(45 /-45 / 0 / 90) \mathrm{s}$ graphite epoxy laminates before edge delamination onset. Hence, the static $G_{C}$ values for granite epoxy have less scatter than was observed for the glass epoxy laminates, and these $G_{c}$ values are not artificialiy elevated. Hence, a linear relationship for eq. 9 may be easily fit to the data using the 
minimum static and fatigue delamination onset values measured (fig.27). For the HM35 graphite $x 751 / 50$ epoxy, a $G_{C}$ value of $137 \mathrm{~J} / \mathrm{m}^{2}$ was obtained, and the slope, $m$, was -10.5 .

Fig. 28 compares the maximum strain energy release rate as a function of cycles to edge delamination onset for the quasi-isotropic graphite epoxy and glass epoxy laminates. The slope, $m$, was the same for both materials. However, although both materials consisted of the same X751 epoxy matrix, the glass/epoxy curves are slightly lower than the graphite/epoxy ones. These lower values were attributed to the glass epoxy delaminating at the fiber-matrix interfaces within the 90 degree plies, instead of failing within the matrix layer between the zero degree and 90 degree plies, similar to the interfacial failure of the hybrid laminates as observed using fractogrophy (fig.9).

Fig. 29 shows the maximum strain energy release rate as a function of cycles to edge delamination onset for the quasi-isotropic hybrid laminates. As noted earlier, edge delamination did not occur under static loading in these hybrid laminates. Hence, a linear fit to eq.9 was not possible. However, fig. 30 shows that the maximum strain energy rolease rate as a function of cycles to edge delamination onset was similar for the quasi-isotropic hybrid and glass epoxy laminates between $10^{2}$ and $10^{6}$ cycles. This was not surprising because the edge delaminations that formed in the 90 degree glass epoxy plies in both laminates were interfacial failures, as evidenced by fiber-matrix separation within the 90 degree ply adjacent to the $0 / 90 \mathrm{ply}$ interface. Hence, the effective $G_{c}$ and $m$ for the hybrid quasi-isotropic laminates was assumed to be identical to the values obtained for the glass epoxy laminates.

Tension Fatigue Life Prediction

To predict fatigue life for the quasi-isotropic glass epoxy laminates and the quasi-isotropic and orthotropic hybrid laminates, the onset of local delaminations from matrix cracks through the laminate thickness was first predicted using eq.11. Local delaminations that occurred between graphite epoxy plies were predicted using $G_{c}$ and $m$ values for graphite epoxy; whereas, local delaminations that occurred between glass epoxy plies, or between adjacent graphite and glass epoxy plies, were predicted using the effective $G_{c}$ and $\mathrm{m}$ values for glass epoxy because they exhibited similar interfacial failures. For the quasi-isotropic laminates, local delaminations formed at the edge and quickly grew normal to the matrix crack along the laminate width (fig.17). Hence, for the quasi-isotropic laminates, $E_{L A M}$ and $E_{L D}$ in eq.11 were replaced by $E^{*}$ and $E_{L D}^{*}$, respectively, because local delaminations initiated a: the edges after edge delaminations had already formed in the $0 / 90$ interfaces.

For the glass epoxy quasi-isotropic laminates, reduced values of $E_{22}$ and $\mathrm{G}_{12}$ discussed previously (table 1) were used to calculate the moduli in eq(11). For the quasi-isotropic hybrid laminates, original lamina properties (tables 2\&3) were used to calculate moduli in eq.11 because no stiffness loss was observed before delamination onset in these laminates. For the orthotropic laminates, the \pm 45 degree graphite epoxy plies developed matrix ply cracks that reduced the laminate modulus before they led to the formation of local delaminations. Furthermore, the non-linearity in the stress-strain curves observed under static tests may have also affected the modulus measured in 
fatigue. Hence, the lamina shear modulus in these layers was reduced by $50 \%$ (table 3) so that the $(45 /-45 / 0)_{\mathrm{s}} \mathrm{E}_{\text {LAM }}$ predicted from laminated plate theory would agree with the modulus, $E_{0}$, measured in fatigue just before the onset of local delamination (table 4 ).

Reductions in effective $\varepsilon_{F}$ for local delaminations accumulating through the thickness were calculated using eq.7, wher $=E_{L A M}$ and $E_{L D}$ were calculated irom laminated plate theory. As previously noted, edge delaminations formed before local delaminations in the quasi-isotropic laminates. Therefore, initially the strain concentration for a local delamination starting at the edge of a quasiisotropic laminate is $K_{E}^{*}$, as determined by eq.8. However, this strain concentration quickly becomes $K_{E}$ when the local delamination forms in the interior. Hence, $K_{\varepsilon}$ values were used to calculate reductions in $\varepsilon_{F}$ for all the laminates.

Figs.31-33 show the range of estimated and measured fatigue lives for the quasi-isotropic glass epoxy laminates, the quasi-isotropic hybrid laminates, and orthotropic hybrid laminates. In some cases the estimated lives are conservative, but in general, very good agreement was observed.

\section{DISCUSSION}

The good agreement between measured and predict?d lives (figs. 31-33) indicates that the through-thickness damage accumulation model can accurately describe fatigut failure for a material whose delamination behavior in fatigue is well characterized, and if stiffness loss is monitored in real time to account for damage growth.

For the glass epoxy laminates, the G vs. Iog I characterization was generated using data from the same laminates whose fatigue 1 ives were being predicted. The fatigue lives of the hybrid laminates, however, were predicted using the $G$ vs. $\log N$ characterization from other glass epoxy and graphite epoxy laminates having the same constituents ( $f$ ibers and matrix) as the hybrids. Ideally, the $;$ vs. $\log N$ characterization should be performed using standardized laboratiry tests [15], and should then be used to predict the fatigue behavior of structural components made of the same material. Hence, for the fatigue life prediction to be accurate, the laboratory characterization should be performed on identical materials (same constituents, fiber volume fraction, cure conditions, etc.) under idfntical environments (Lemperature, moisture, etc.) and lotding conditions (load rate, R-ratio, frequency, etc.) as the structure. The influence of other material, environmental, and loading variables has been examined [20-22]. However, most of this work has been perf'ormed for static toughness and/or delamination growth. Much work still needs to be done to determine the influence of these variables on delamination onset in fatigue.

Furthermore, the fatigue life methodology outlined in this paper for composite laminates took advantage of the real-time measurement of stiffness loss that was attainable in the laboratory for these simple coupon tests. For most structural applications, however, this information may not be available. However, in the absence of accurate damage growth and/or stiffness loss information, a similar, but more conservative, Damage Threshold/Fail Safety approach may be used for composite structures [23]. 


\section{CONCLUSIONS}

A tension fatigue life prediction methodology for composite laminates is presented. Tension fatigue tests were conducted on quasi-isotropic and orthotropic glass epoxy, graphite epoxy, and glass/graphite epoxy hybrid laminates. Edge delamination onset data were used to generate plots of strain energy release rate as a function of cycles to delamination onset. These plots were then used along with strain energy release rate analyses of delaminations initiating at matrix cracks to predict local delamination onset. Stiffness loss was measured experimentally to account for the accumulation of matrix cracks and for delamination growth. Fatigue failure was predicted by comparing the increase in global strain resulting from stiffness loss to the decrease in laminate failure strain resulting from delaminations forming at matrix cracks through the laminate thickness. Good agreement between measured and predicted lives indicated that the through-thickness damage accumulation model can accun-tely fatigue fatigue fallure for laminates where the delamination onset behavior in to account is well characterized, and stiffness loss can be monitored in real time

\section{ACKNOWLEDGEMENT}

This work was performed as part of a Memorandum of Understanding (MOU) on Helicopter Aeromechanios and Structures between the U.S. Department of the Army and the Italian Ministry of Defense. 
REFERENCES

1. O'Brien, T.K., "Characterization of Delamination Onset and irowth in a Composite Laminate," Damage in Composite Materials, AS?M STP 755, 1982, pp. 140-167.

2. O'Brien, T.K., "Analysis of Local Delamination: and Their Influence on Composite Laminate Behavior," Delamination and Debonding of Materials, ASTM STP 876,1985 , pp. 282-297.

3. O'Brien, T.K., "Generic Aspects of Delamination in Fatigue of Composite Materials", Journal of the American Helicopter Society, Vol. 32, No. 1, January 1987, pp. 13-18.

4. Caslini, M., Zanotti, C., and $0^{\prime}$ Brien, T.K., "study of Matrix Cracking and Delamination in Glass/Epoxy Laminates," J. of Composites Technology \& Research, Vol.9, No.4, Winter 1987, pp.121-130.

5. O'Brien, T.K, , Crossman, F.W., and Ryder, J.R., "Stiffness, Strength, and Fatigue Life Relationships for Composite Laminates," Proceedings of the Seventh Annual Mechanics of Composites Review, Dayton, ohio, 1981, AFWAL-TR-82-4007, April 1982, pp. 79-90.

6. O'Brien, T.K., "The Effect of Delamination on the Tensile Strength of Unnotched, Quasi-Isotropic, Graphite Epoxy Laminates," Proceedings of the SESA/JSME: Joint Conference on Experimental Mechanics, Part I, Honolulu, Hawai i, May 1982, SESA, Brookfield Center, CT, pp. 236-243.

7. O'Brien, T.K., "Tension Fatigue Behavior of Quasi-Isotropic Graphite/Epoxy Laminates," Proceedings of the Third RISO International Symposium on Metallurgy and Materials Science: Fatigue and Creep of Composite Materials, September 1982, RISO National Laboratory, Roskilde, Denmark, pp. 259--264.

8. Ryder, J.T., and Crossman, F.W., "A Study of Stiffness, Residual Strength, and Fatigue Life Relationships for Com osite Laminates," NASA CR-172: 11 , October 1983.

9. Reifsnider, K.l., Henneke, E.G., and Stinchcomb, W.W., "DefectProperty Relationships in Composite Materials," FML-TR-76-81, Air Force Materials Laboratory, Dayton, Ohio, 1979.

10. Bader, M.G., Balley, J.E., Parvizi, A., and Curtis, P.T., "The Mechanisms of Initiation and Development of Damage in Multi-Axial Fiber-Reinforced Plastic Laminates," Mechanical Beha\%ior of Materials, Proceedings of the Third International Conference on Materials, ICM 3 , Vol.3, 1979.

11. O'Brien, T.K., "Interlaminar Fracture of Composites," J. of the Aeronalutical Society of India, Vol. 37, No.1, Feb. 1985, pp. 61-70. 
12. O'Brien, T.K., "Mixed-Mode Strain Energy kelease Rate Effects on Edge Delamination of Composites," Ef fects of Defectizin Composite Materials, ASTM STP 836, 1984, pp. $125-142$.

13. O'Brien, T.K., "Fatigue Delamination Behavior of PEEK Thermoplastic Composite Laminates," J. of Reinforced Plastics, Vol.7, No.4, July, 1988, pp. 341-359.

14. O'Brien, T.K., Murri, G.B., and Salpekar, S.A., "Interlaminar Shear Fracture Toughness and Eatigue Thresholds for Composite Materials," ASTM STP 1012, 1988 (Also in NASA TM 89157, USAAVSCOM TM 87-B-9, August 1987).

15. Martin, R.H. and Murri, G.B., "Characterization of Mode I and Mode I I Delamination Growth and Thresholds in Graphite/PEEK Compoijles," NASA TM 10057\%, USAAVSCOM TM 88-B-011, April 1988.

16. Adams, D.F., Zimmerman, R.S., and Odem, E.M., "Determining Frequency and Load Katio Effects on the Edge Delamination Test in Griphite Epoxy Composites," Toughened Composites, ASTM STP 937, 1987, pp. '4i-259.

17. Poursartip, A., "The Characterization of Edge Jelamination Growth in Composite Laminates Under Fatigue Loading," Toughened Composites, ASTM STP 937, 1987, p.222.

18. Jamison, R.D., Schulte, K., Reifsnider, K.L., and Stinchcomb, W.W., "Characterization and Analysis of Damage Mechanisms in Tencion-Tension Fatigue of Graphite/Epoxy Laminates," Effects of Defects in Composite Materials, ASTM STP 836, 1984, pp.21-55.

19. Sun, C.T., and Yoon, K.J., "Characterization of Elastic-Plastic Properties of AS4/APC-2 Thermoplastic Composite, "Purdue University Report CML 88-3, August, 1988.

20. Russei I, A.J. and Street, K.N., "Moisture and remperature Effects on the Mixed Mode Delamination Fracture of Unidirectional Graphita/Epoxy," Delamination and Debonding of Materials, ASTM STP 876 , October 1985 , pp. 349-370.

21. Aliyu, A.A., and Daniel, I.M., "Effects of Strin Rate on Delamination Fracture Toughness of Graphite/Epoxy," Delaminition and Debonding of Materials, ASTM STP 876,1985 , pp.336-348.

22. Danie1, I.M., Shareef, I., and Aliyu, A.A., "Rate Effects on Delamination Fracture Toughness of a Toughened Graphite/Epoxy," Toughened Composites, ASTM STP 937, pp.260-274.

23. OBrien, T.K., "Towards a Damage Tolerance Philosophy for Composite Materials and Structures," NASA TM 100548, USAAVSCOM TM 88-B-009, March 1988. 


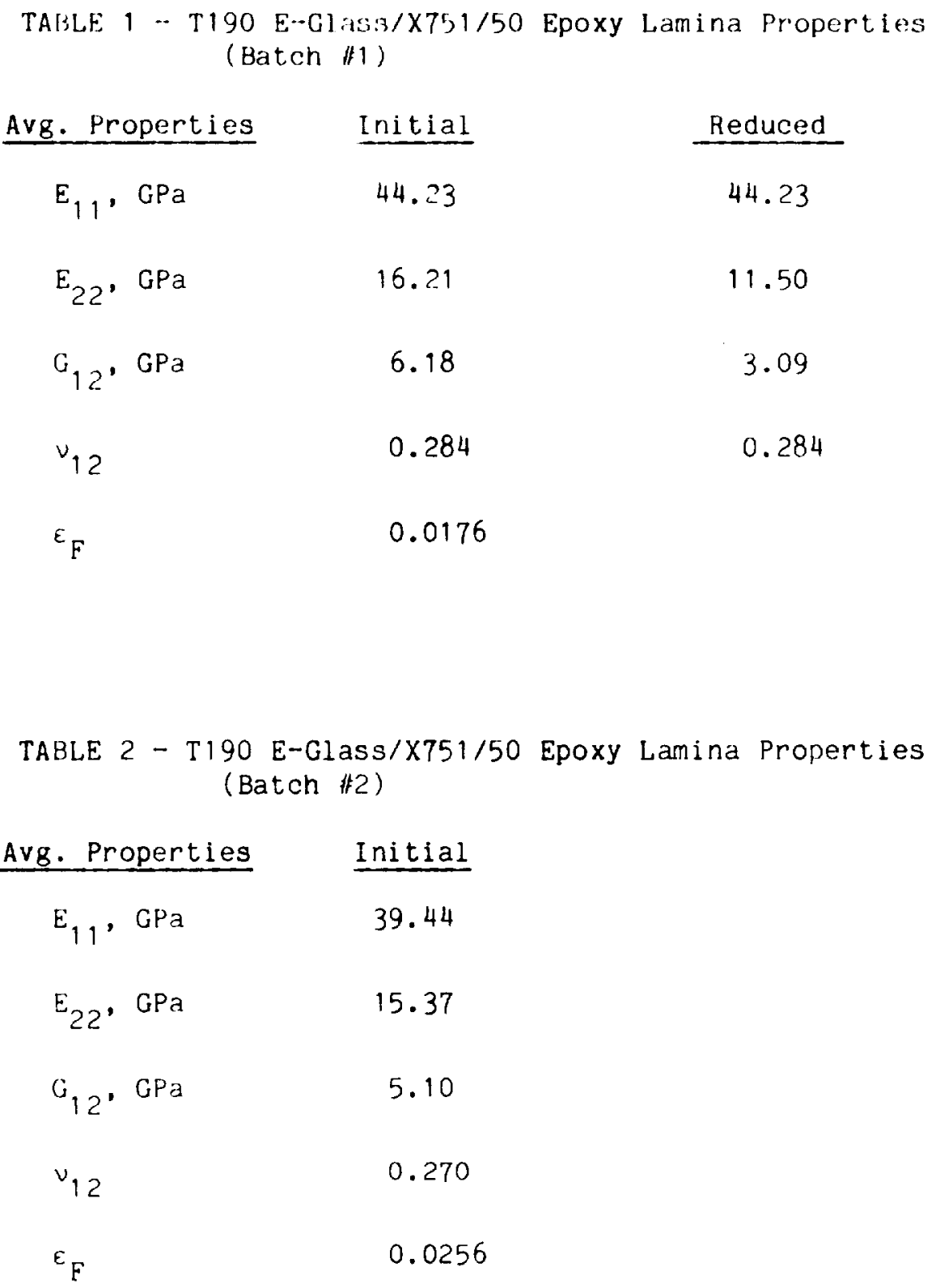


TABLE 3 - HM35 Graphite X751/50 Epoxy Lamin.1 Properties

$\begin{array}{ccc}\text { Avg. Properties } & & \text { Initial } \\ E_{11}, \mathrm{GPa} & 152.50 & 152.50 \\ E_{22}, \mathrm{GPa} & 7.50 & 7.50 \\ \mathrm{G}_{12}, \mathrm{GPa} & 4.12 & 2.06 \\ \nu_{12} & 0.246 & 0.246 \\ \varepsilon_{\mathrm{F}} & 0.00719 & \end{array}$

TABLE 4 - LAMINATE PROPERTIES

\begin{tabular}{|c|c|c|c|c|c|c|}
\hline MA TER I AL & LAYUP & $\begin{array}{c}\text { AVG. } \\
\varepsilon_{E}\end{array}$ & $\frac{\text { AVG. INIT If }}{\mathrm{E}_{0}(\mathrm{GPa})}$ & $\frac{\text { L MODUL I }}{E_{\text {LAM }}}$ & $\frac{\text { MODUL I BEFORE }}{E_{0}(\mathrm{GPa})}$ & $\frac{\text { DELAMINATION }}{E_{\text {LAM }}}$ \\
\hline Glass & {$[ \pm 45 / 0 / 90]_{s}$} & 0.01500 & 23.9 & 25.2 & 21.2 & 21.0 \\
\hline Graphite & {$[ \pm 45 / 0 / 90]_{s}$} & 0.00663 & 57.5 & 56.7 & $\cdots$ & $\cdots$ \\
\hline Hybrid & {$[ \pm 45 / 0 / 90]_{\mathrm{s}}$} & 0.00695 & 52.1 & 51.8 & $\ldots$ & $\cdots$ \\
\hline Hybrid & {$[ \pm 45 / 0]_{s}$} & 0.02340 & 24.4 & 25.6 & 21.5 & 21.6 \\
\hline
\end{tabular}




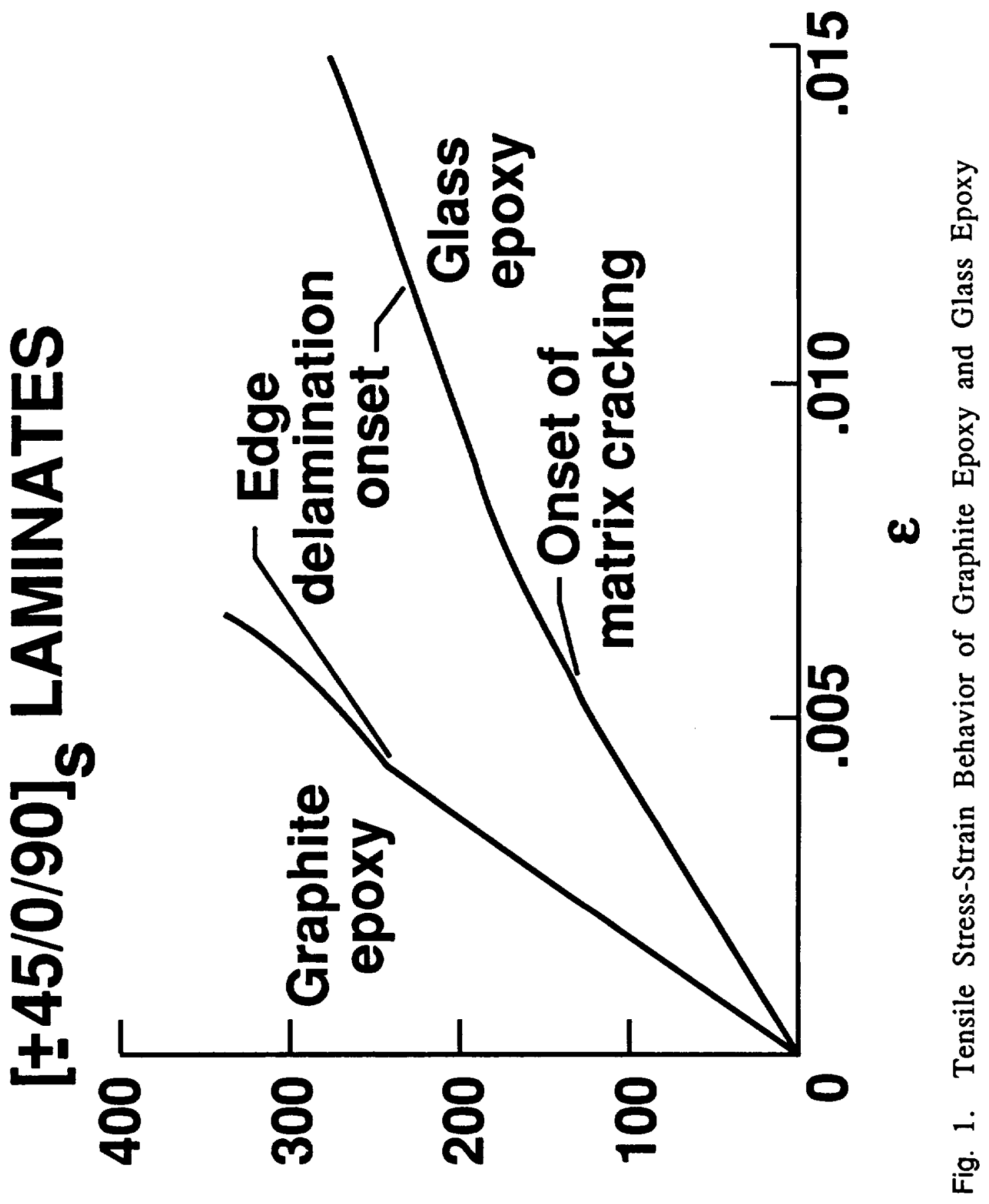

8

6 


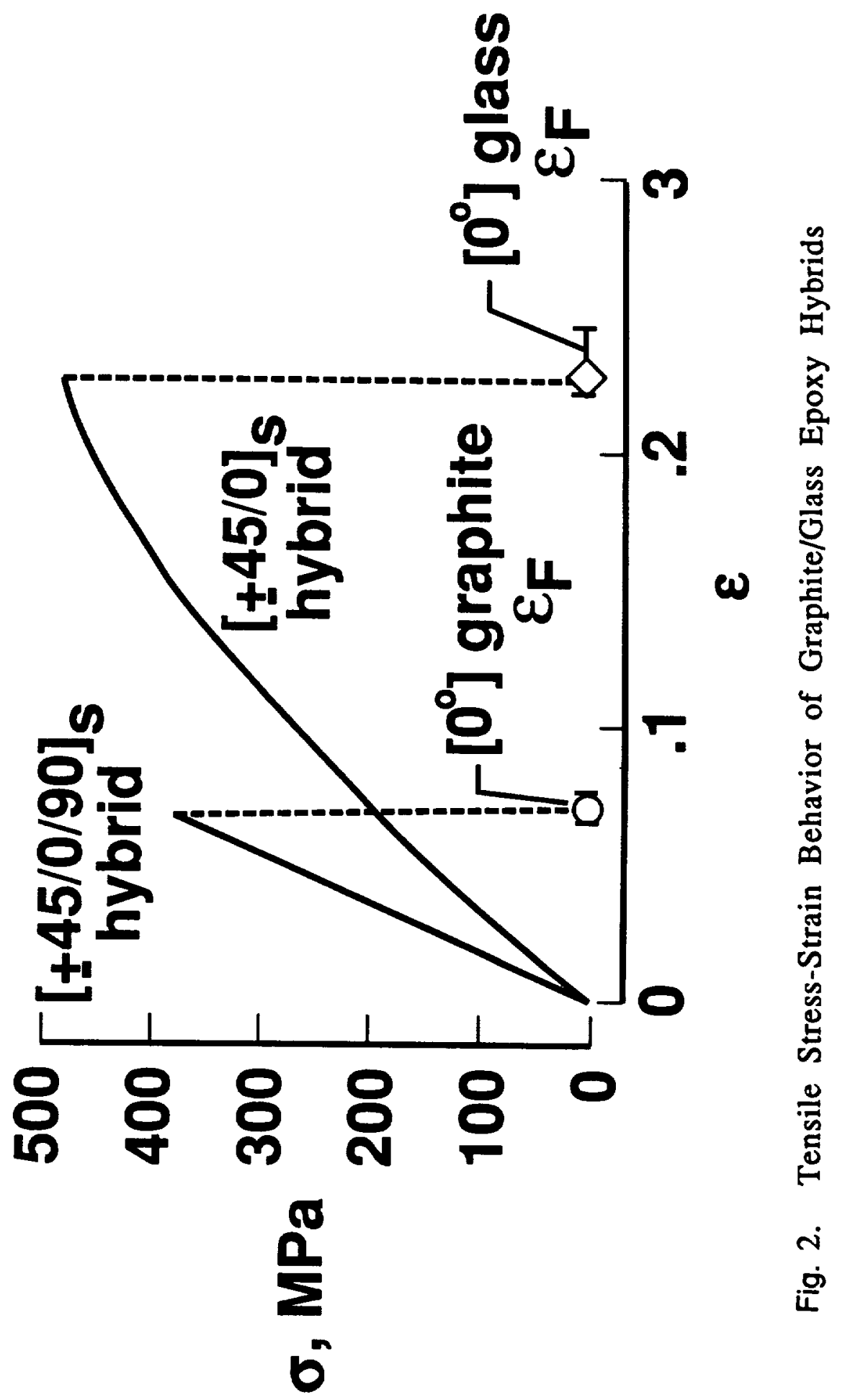




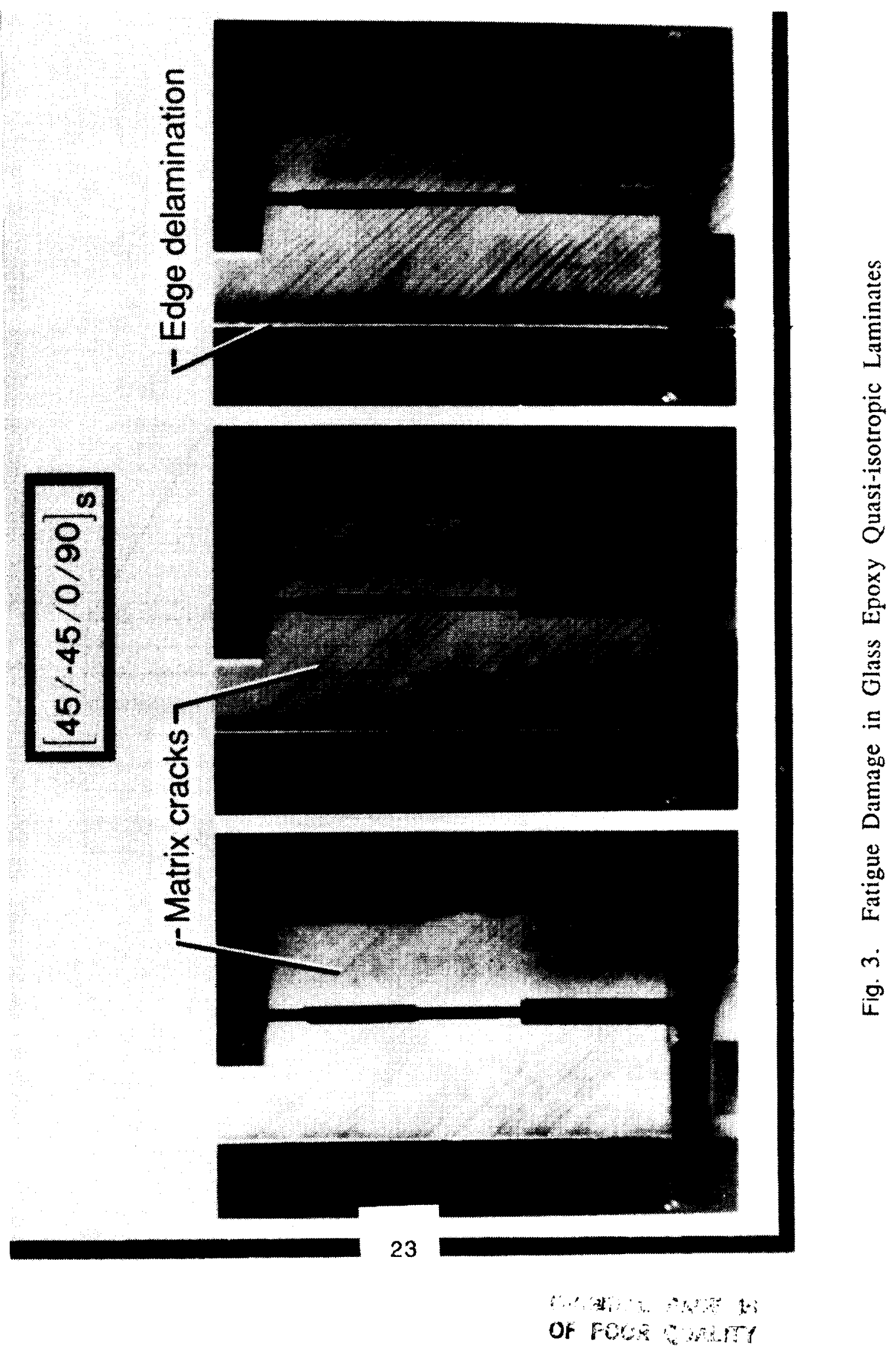




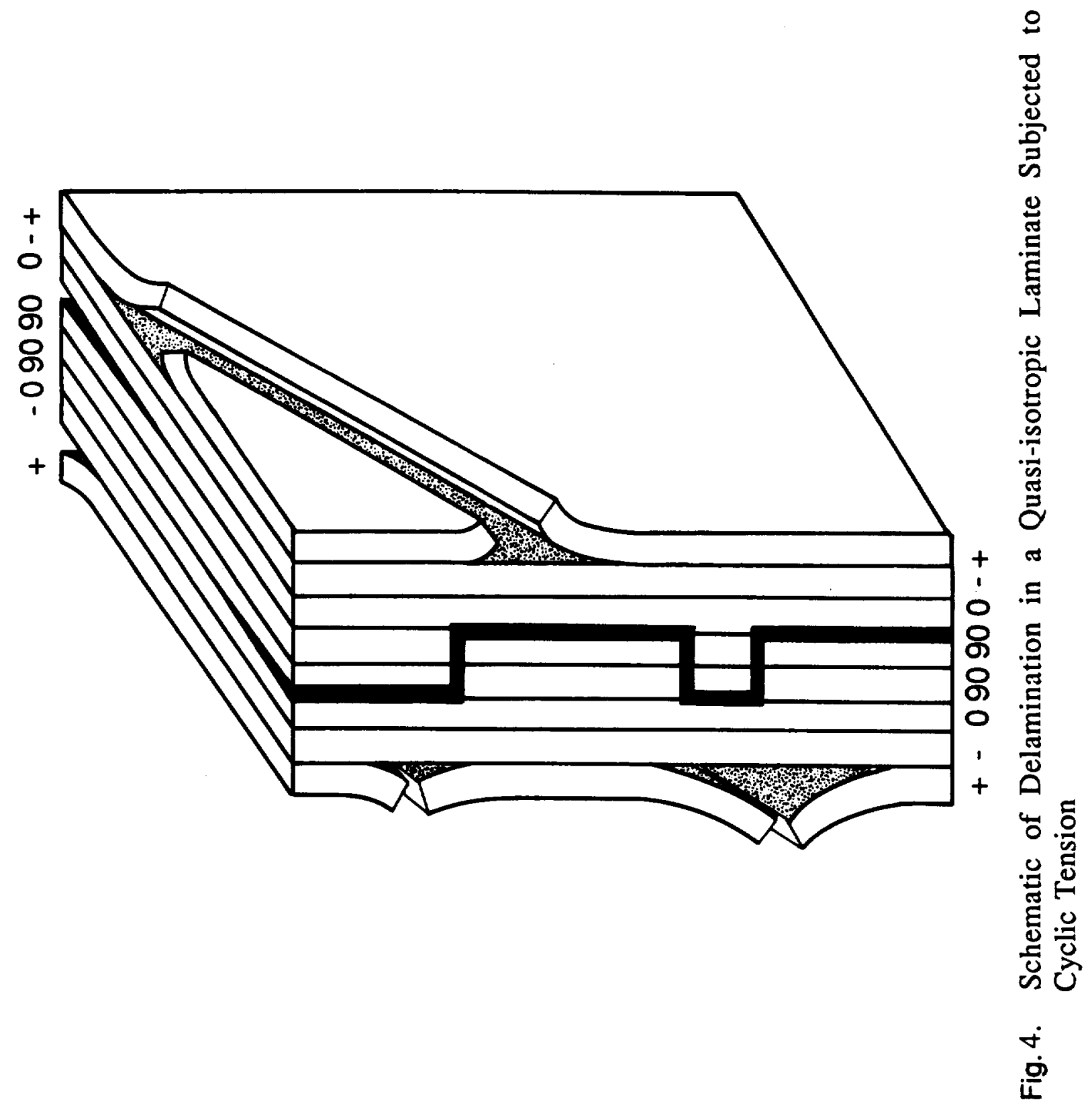




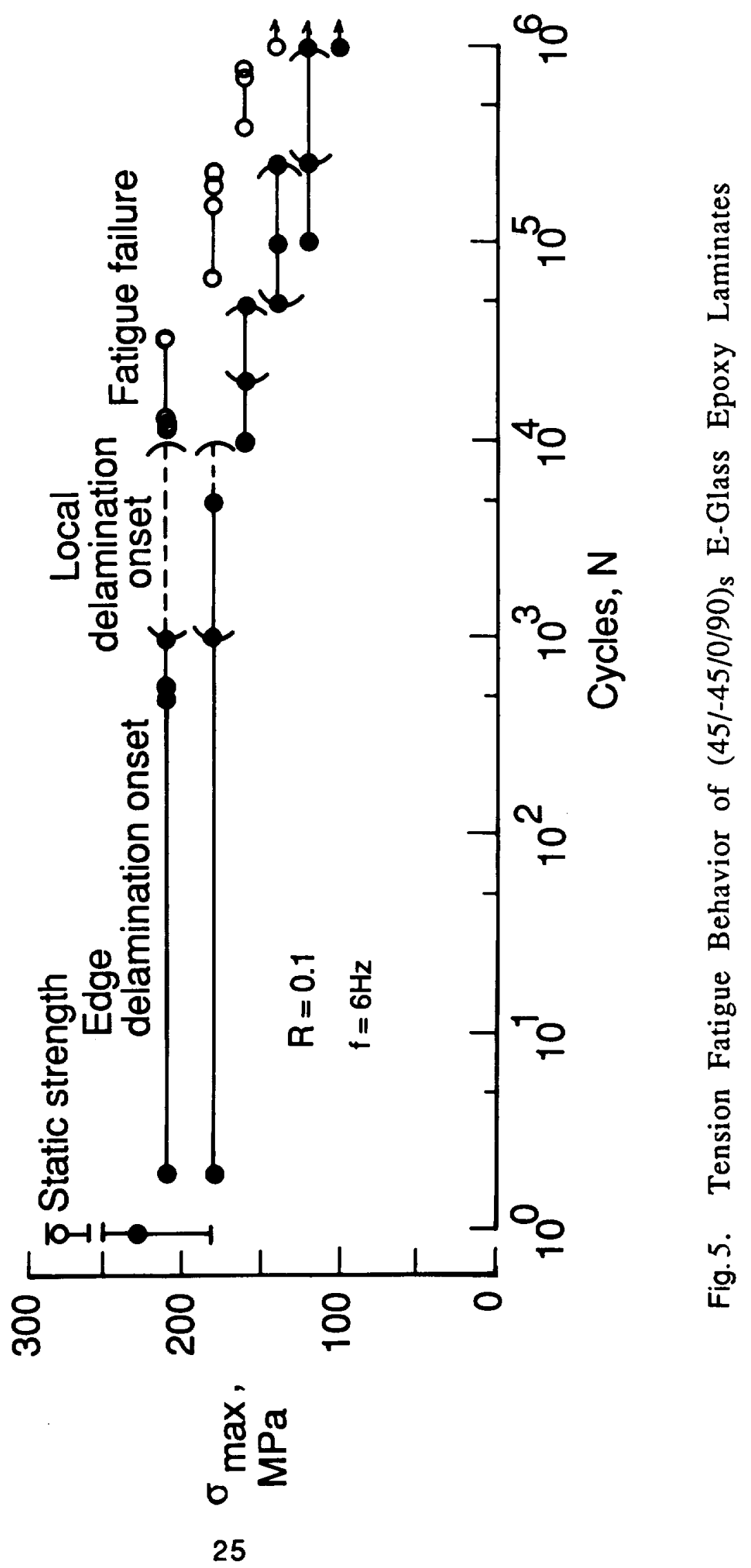




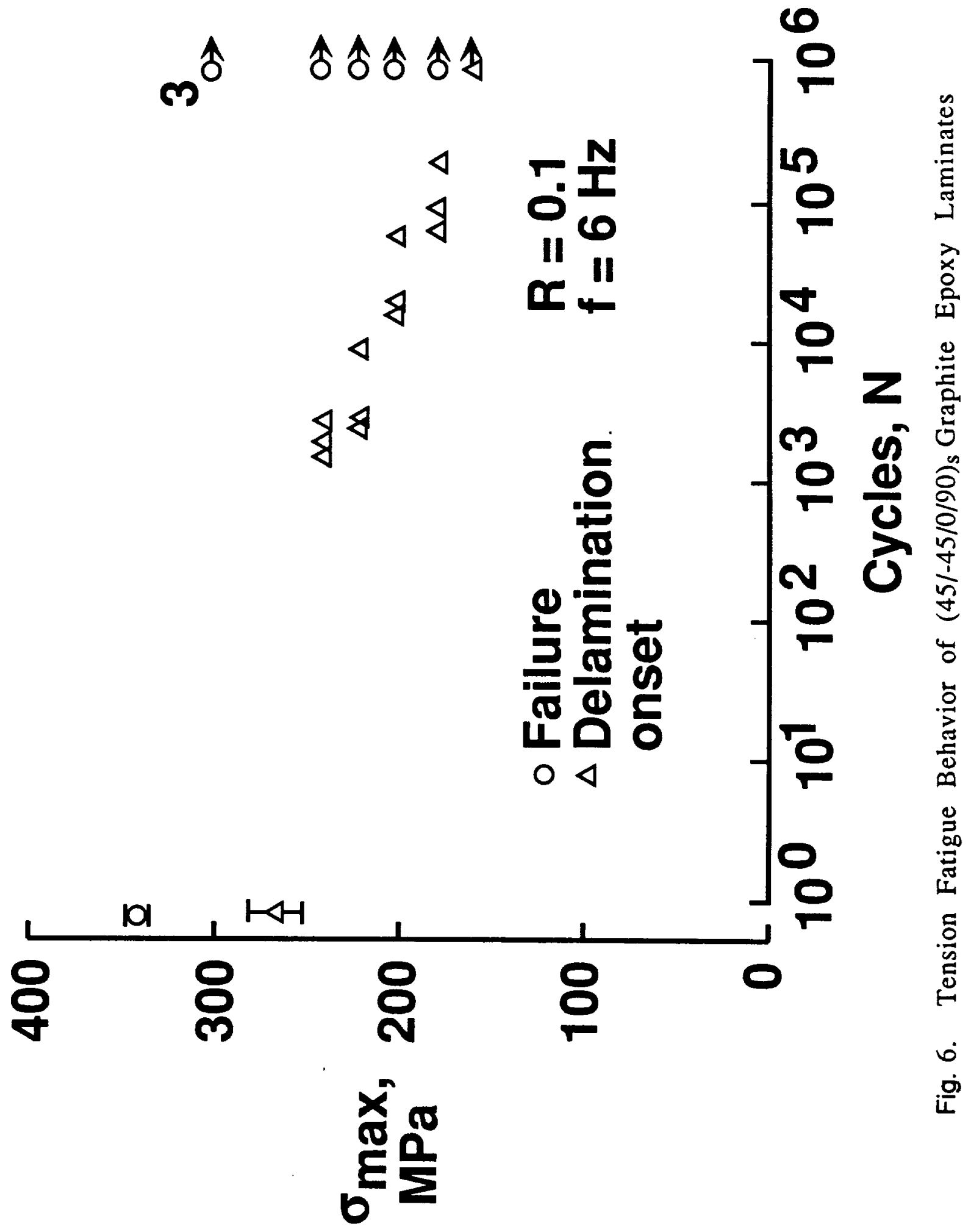




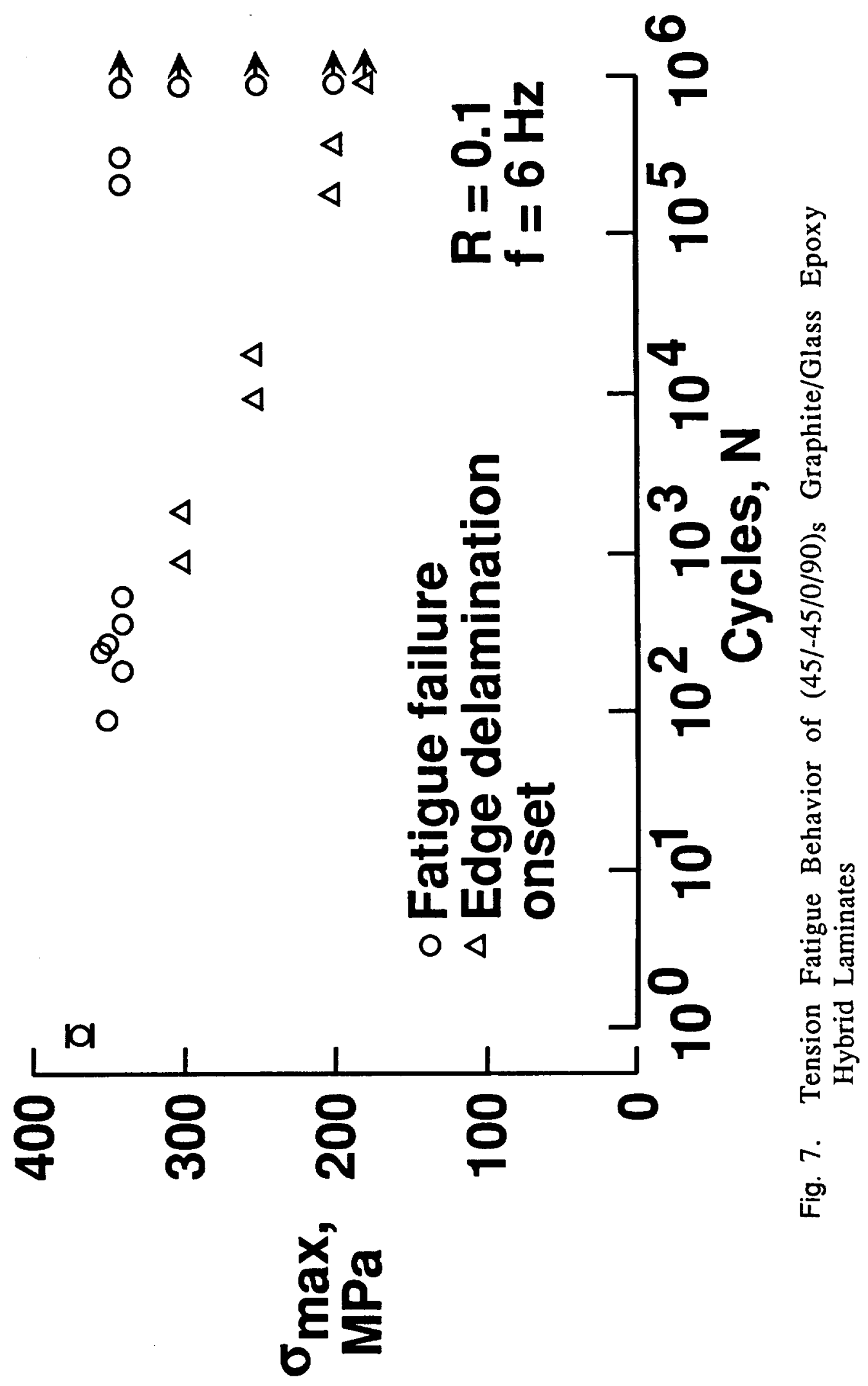




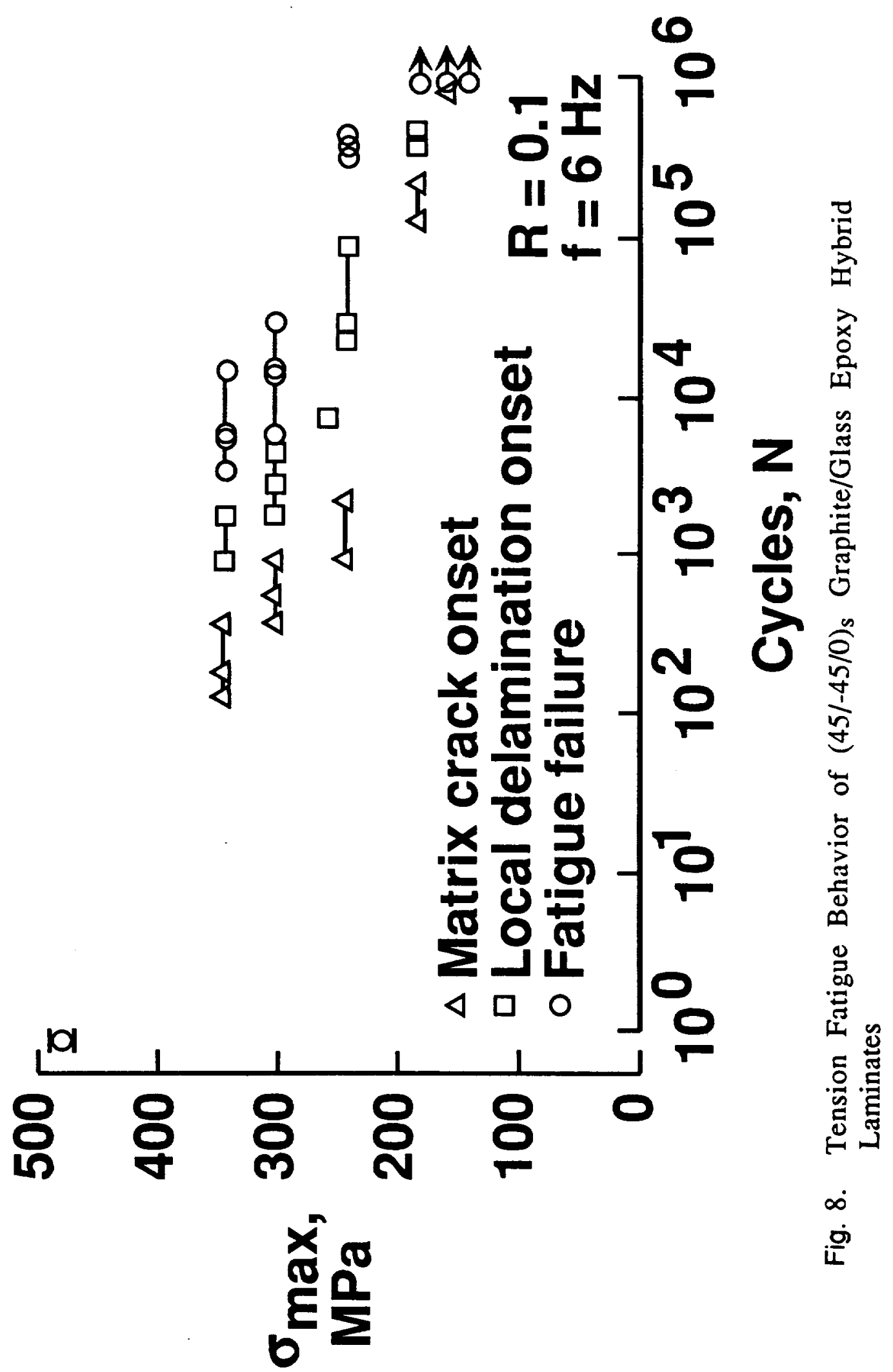


ORIGINAL PAGE IS

OF. POOR QUALITY

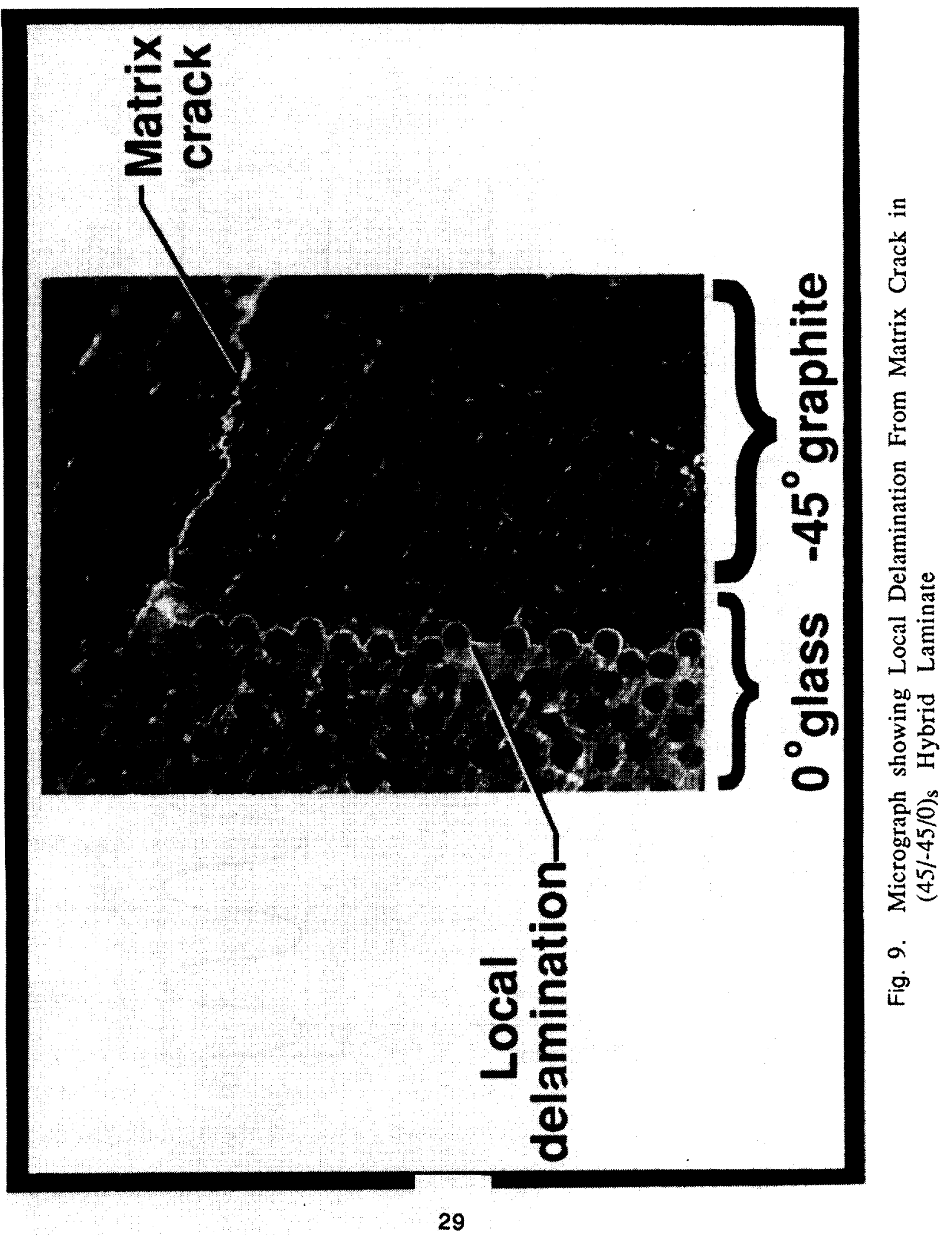



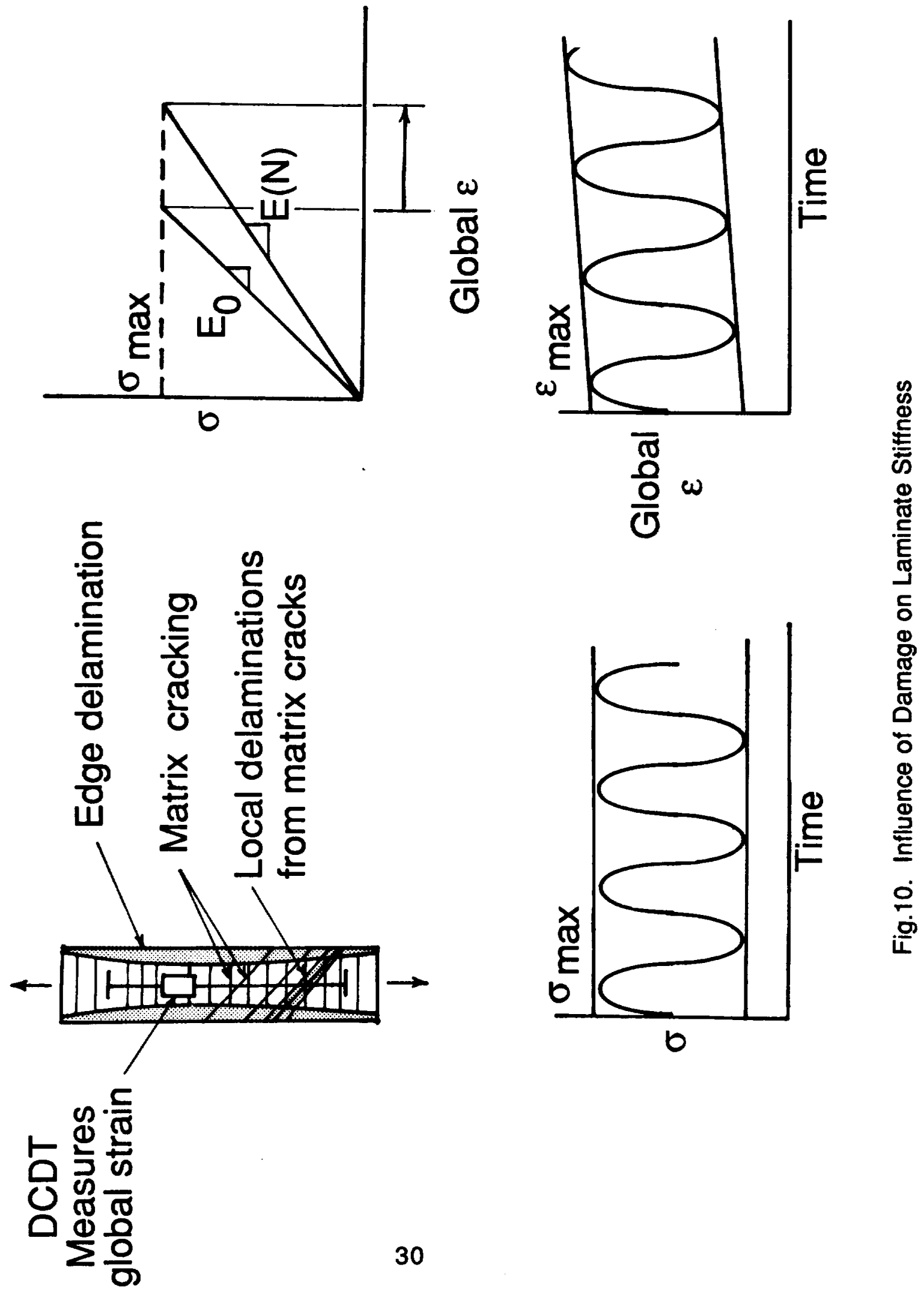


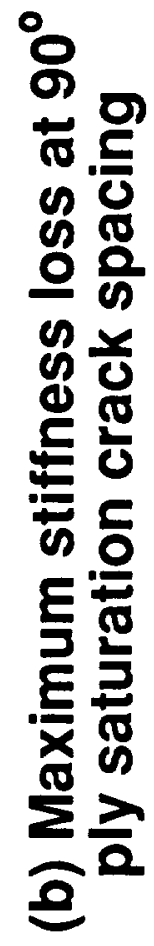

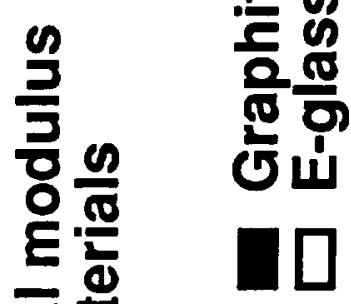
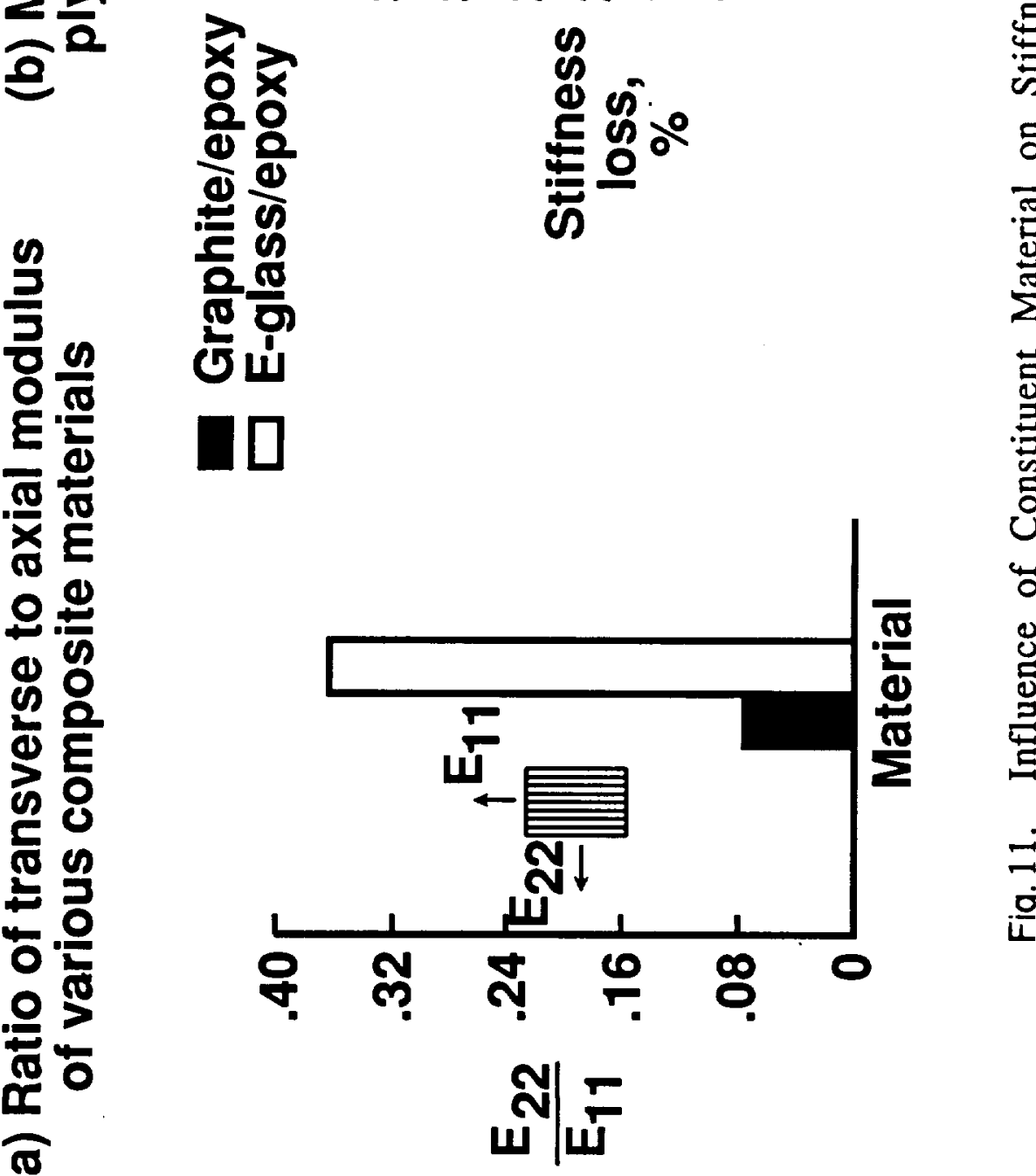

ㅎำ

口

(10)

II) 


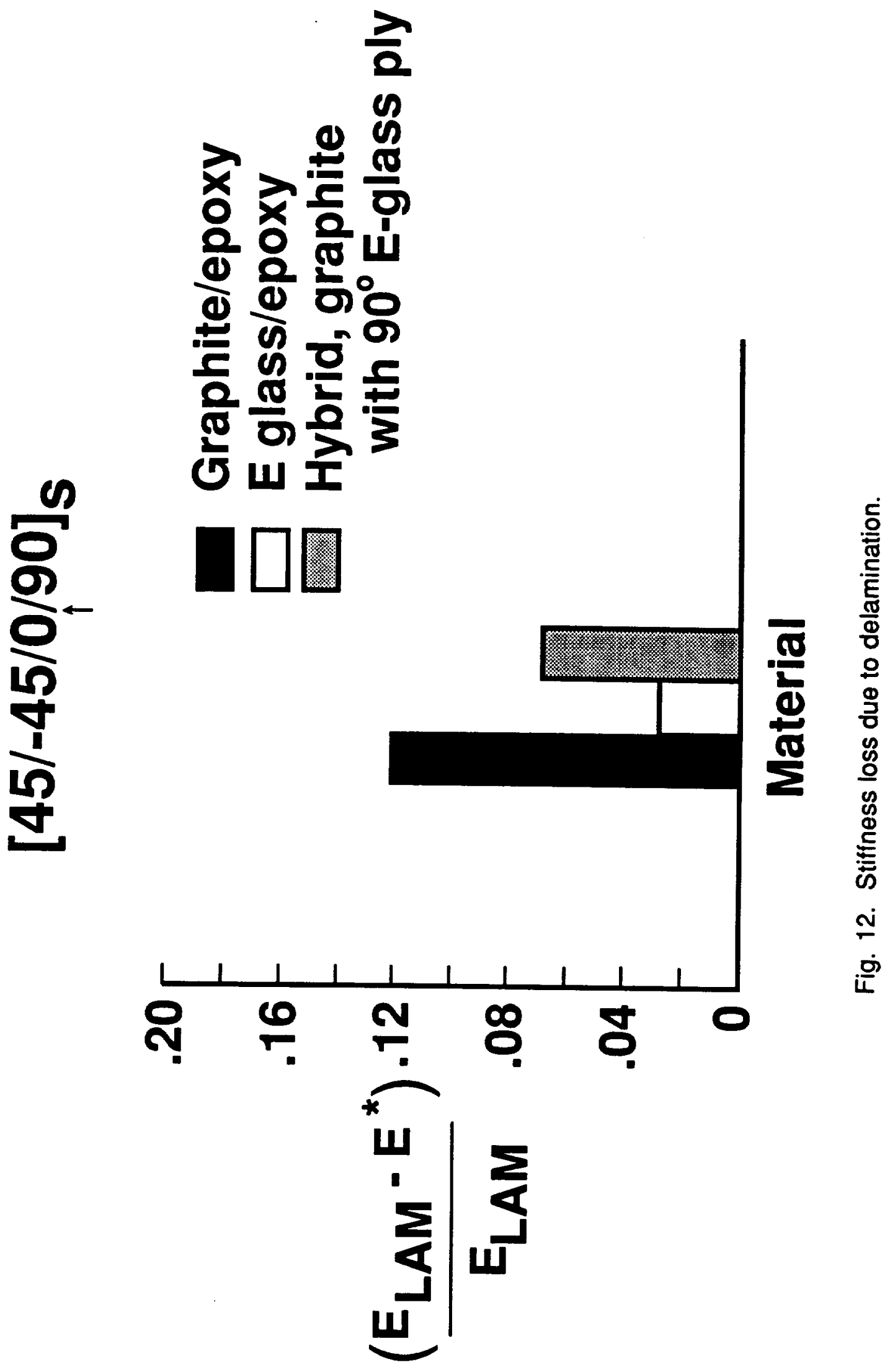




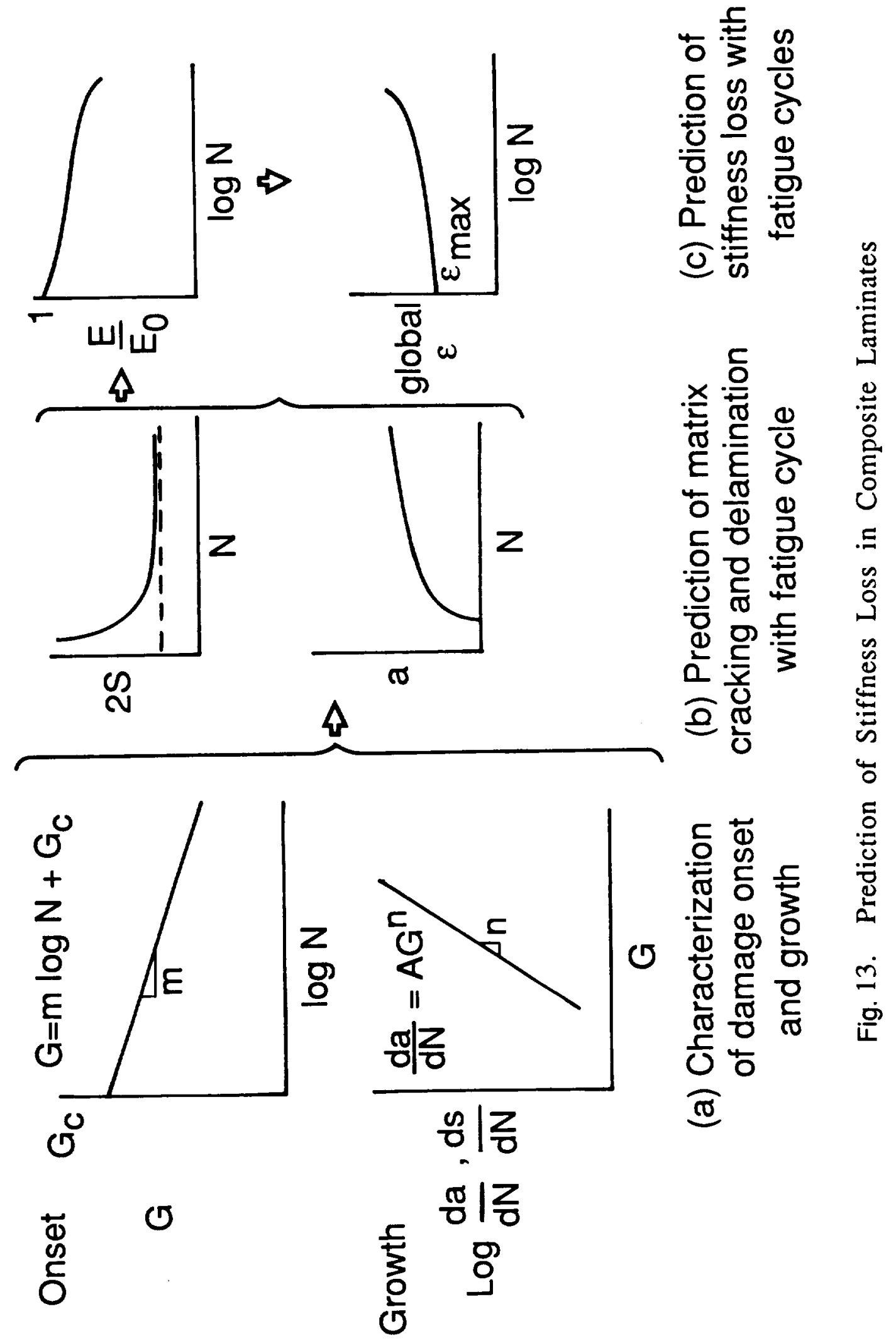




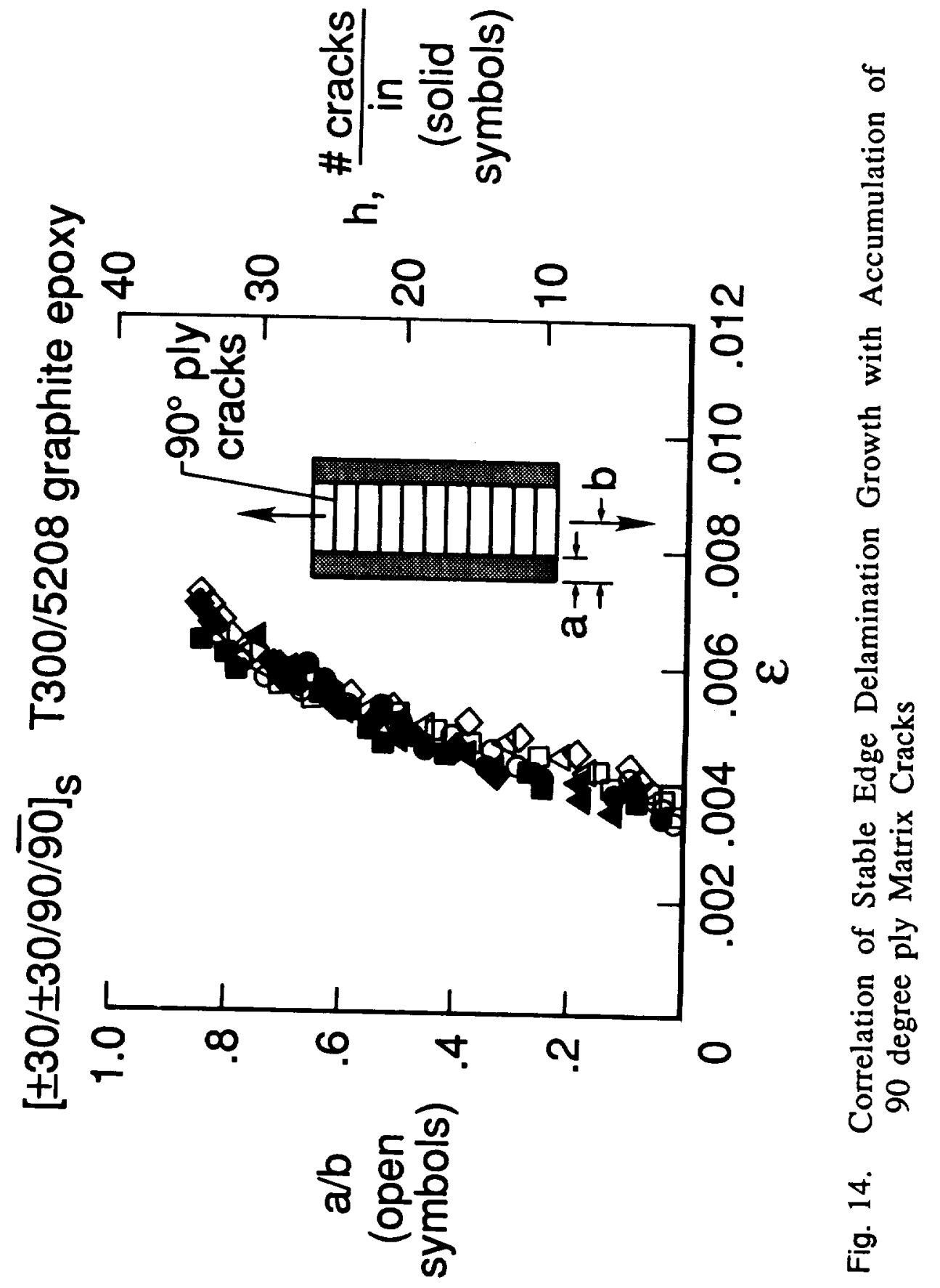




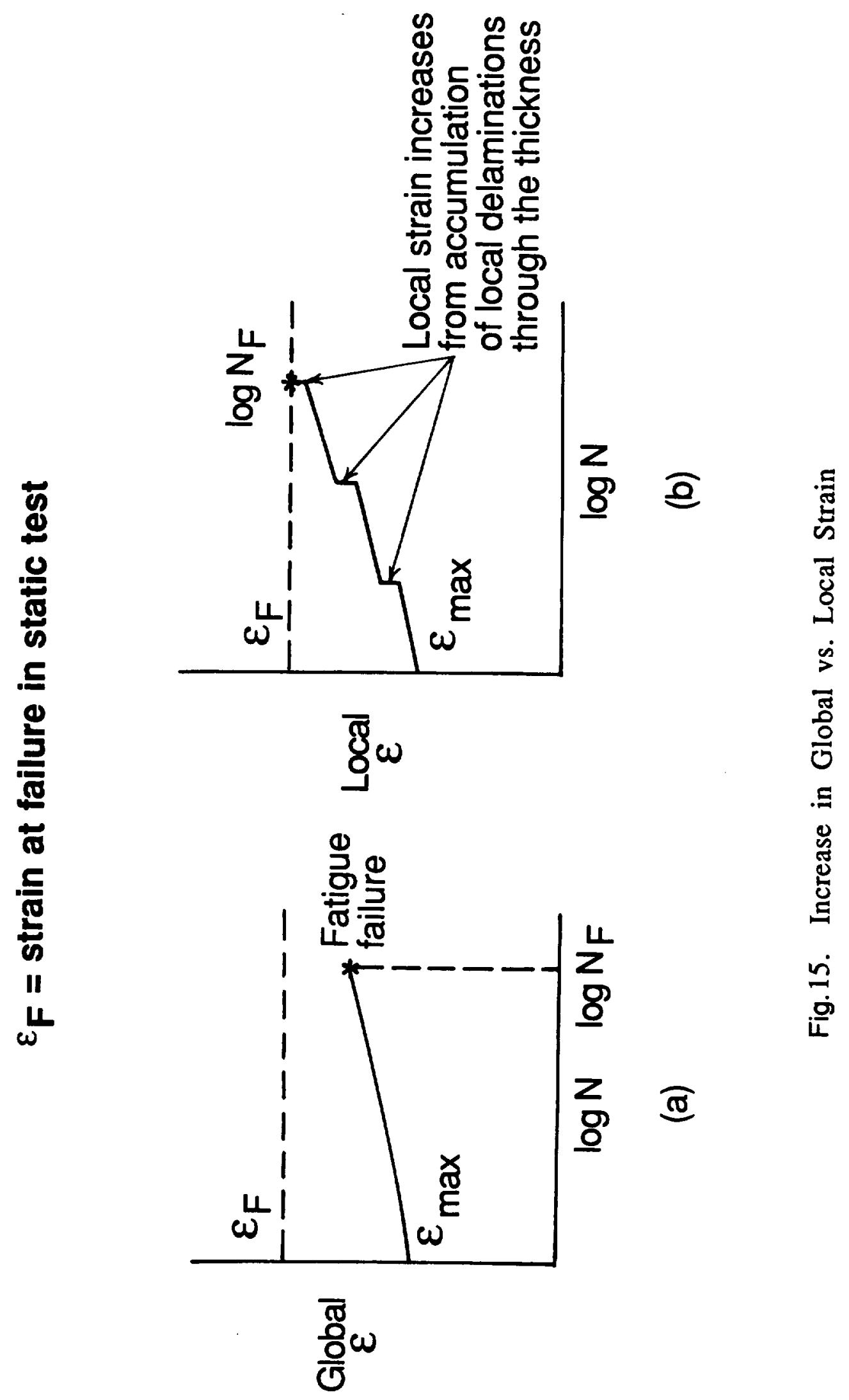




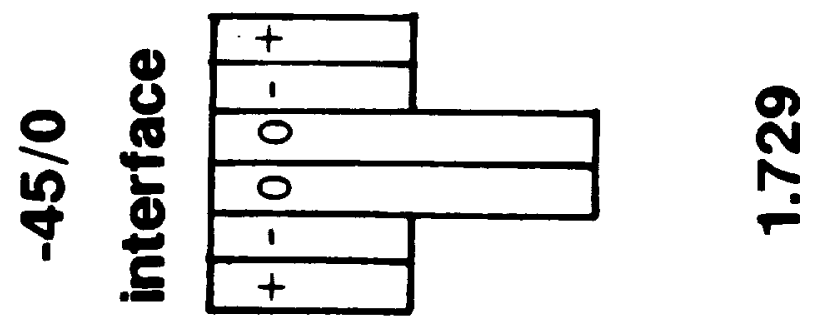

$+$

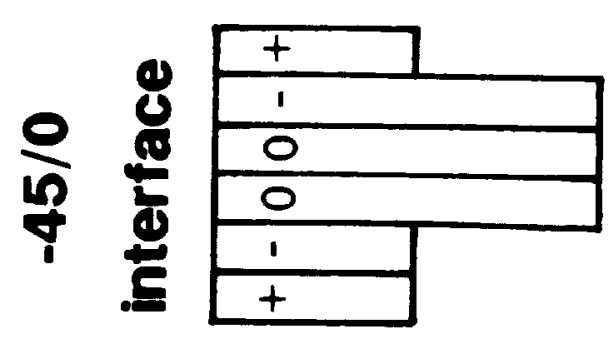

$\stackrel{1}{*}$

$+$
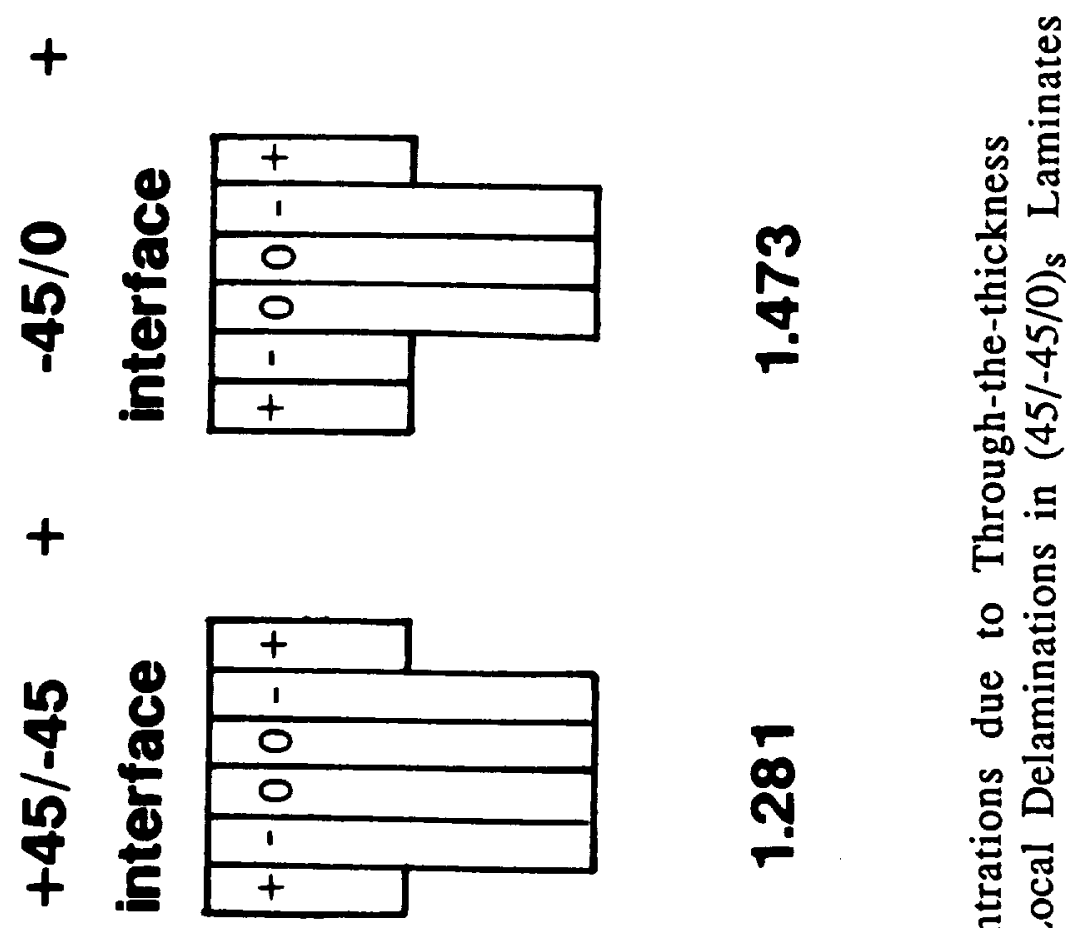

-

은.드

E

은

0 .

$\stackrel{8}{\infty}$

$+$
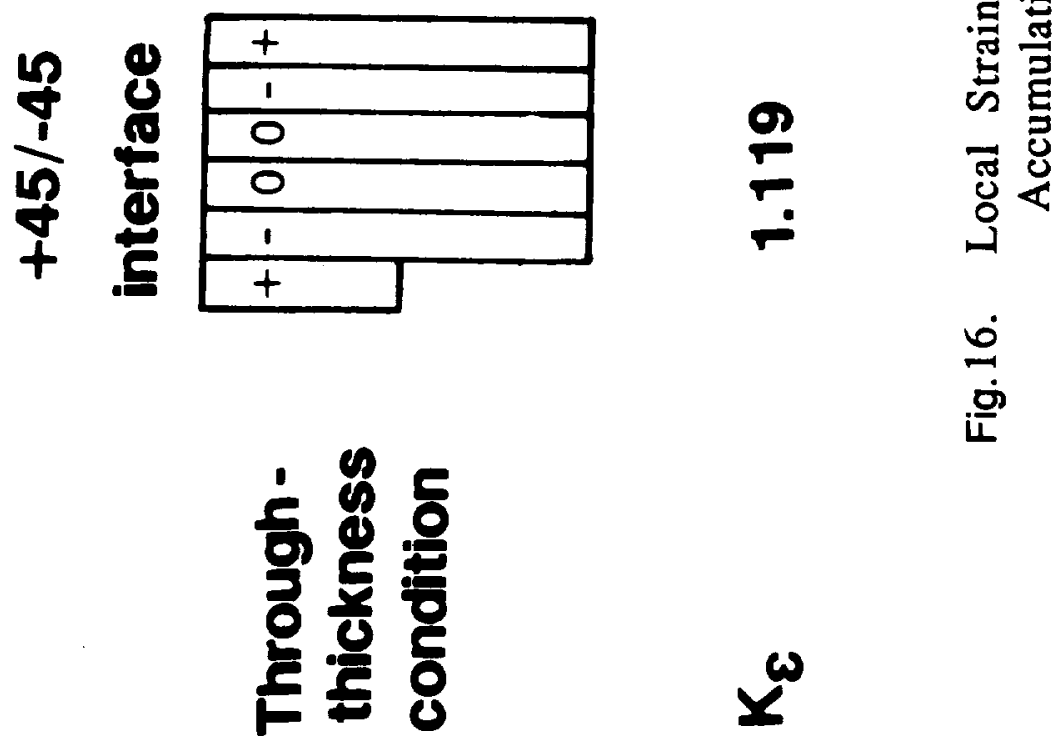

$\underset{i}{\dot{0}}$ 

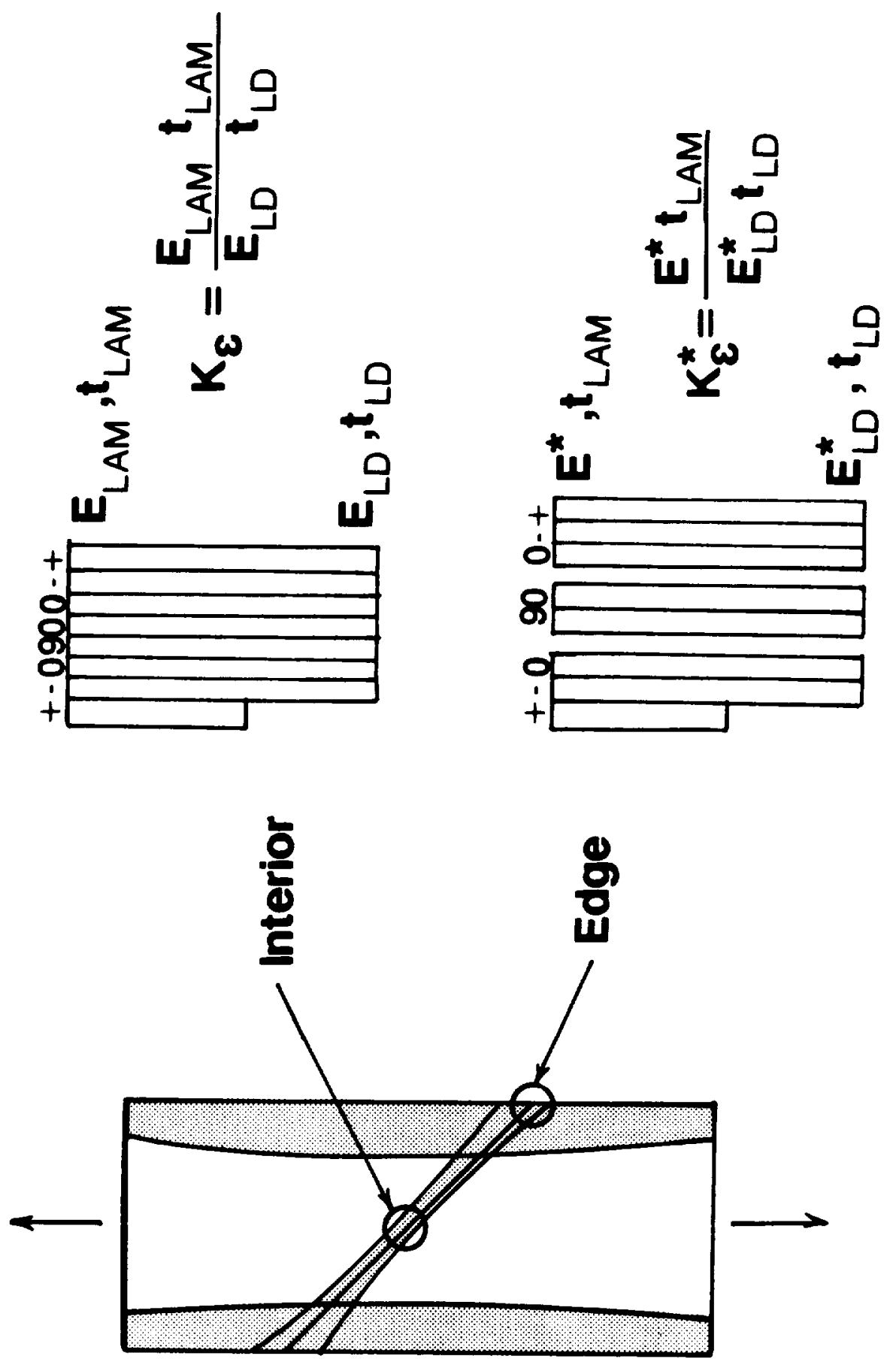

烍

$\underset{\substack{n \\ \frac{n}{n}}}{\frac{n}{n}}$

.5

ํㅗㅇ

苂

$\stackrel{0}{=}$

号

㿣

w

I

iq 


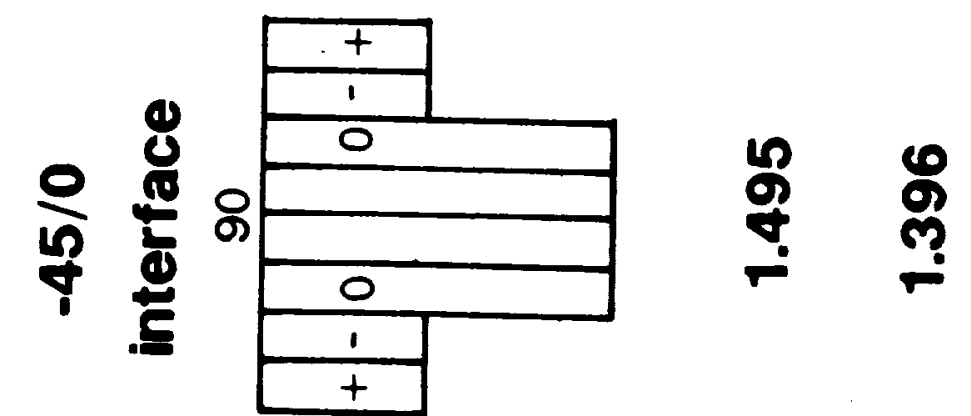

$+$

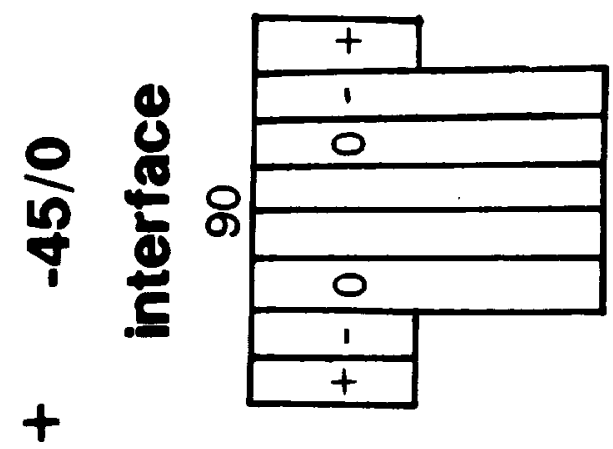

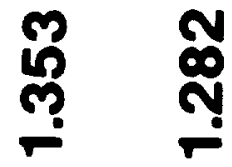
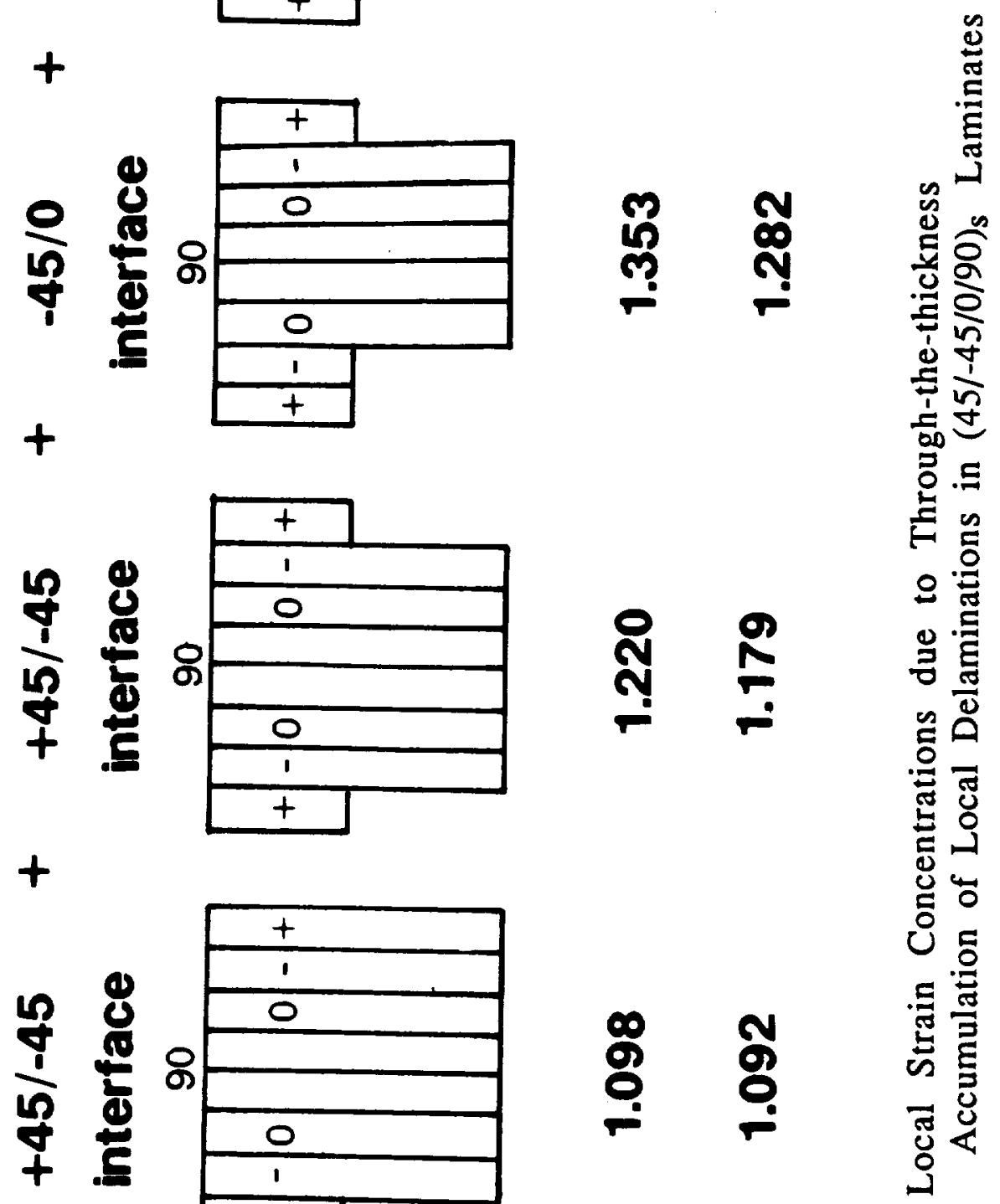

ํ.

$+$

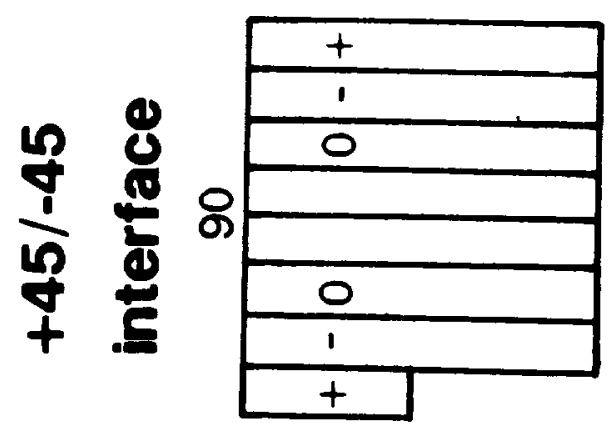

$\stackrel{\infty}{\beta}$

$\stackrel{\infty}{\dot{0}}$

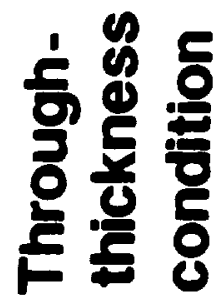




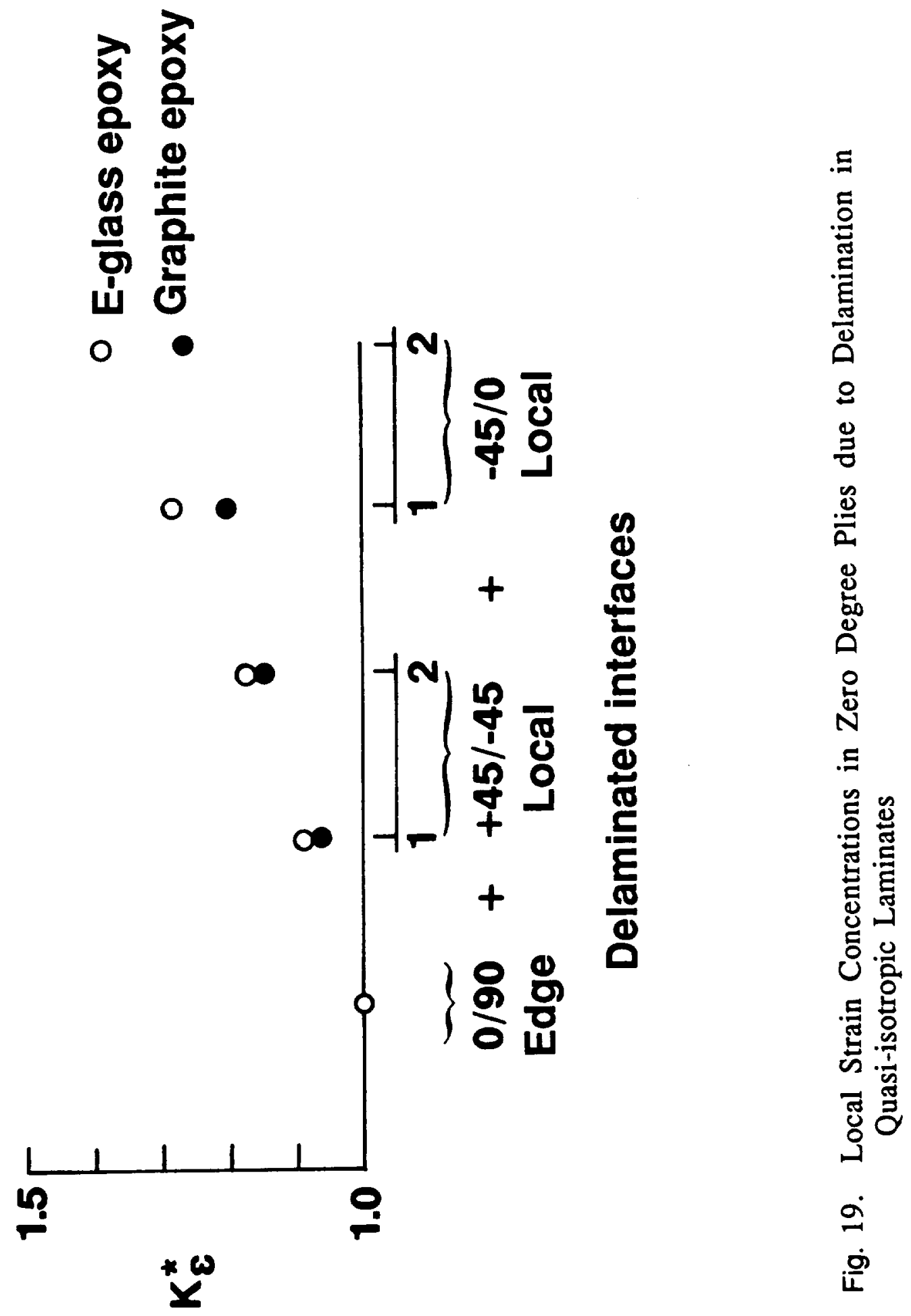




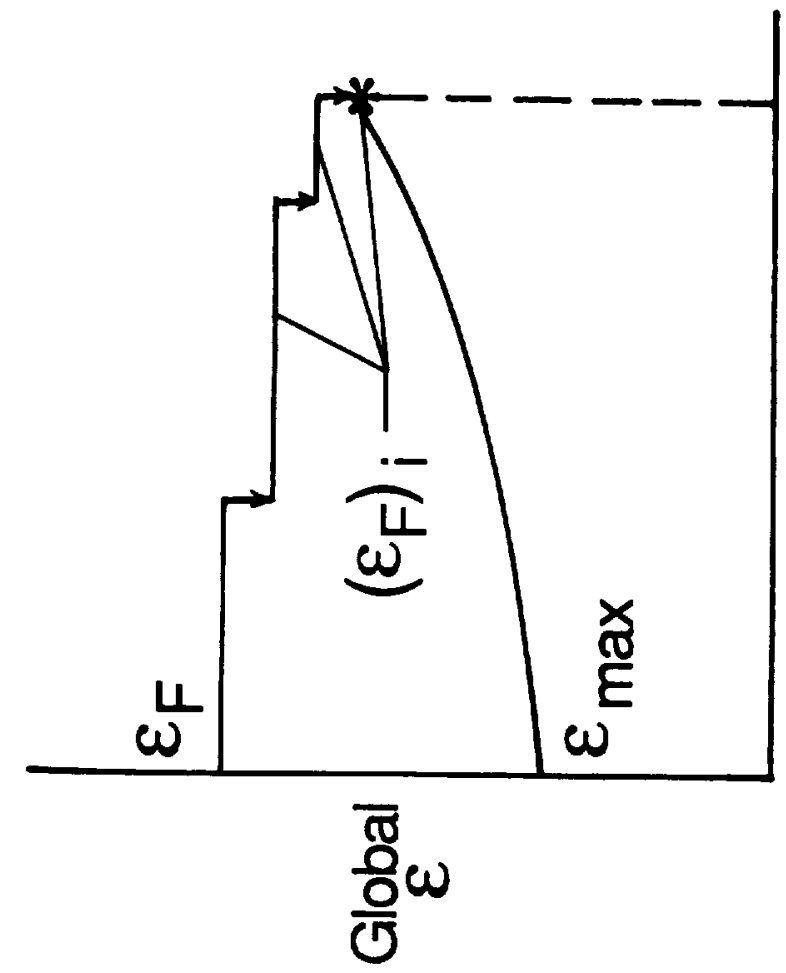

$\frac{1}{Z}$

u| $\mid \frac{\bar{\omega}}{\underline{x}}$

$\sum_{0}^{2} \frac{11}{\frac{\omega}{0}}$

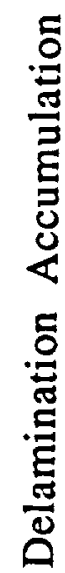

కై

$\rho \mathscr{S}_{\tilde{S}}^{\tilde{y}}$

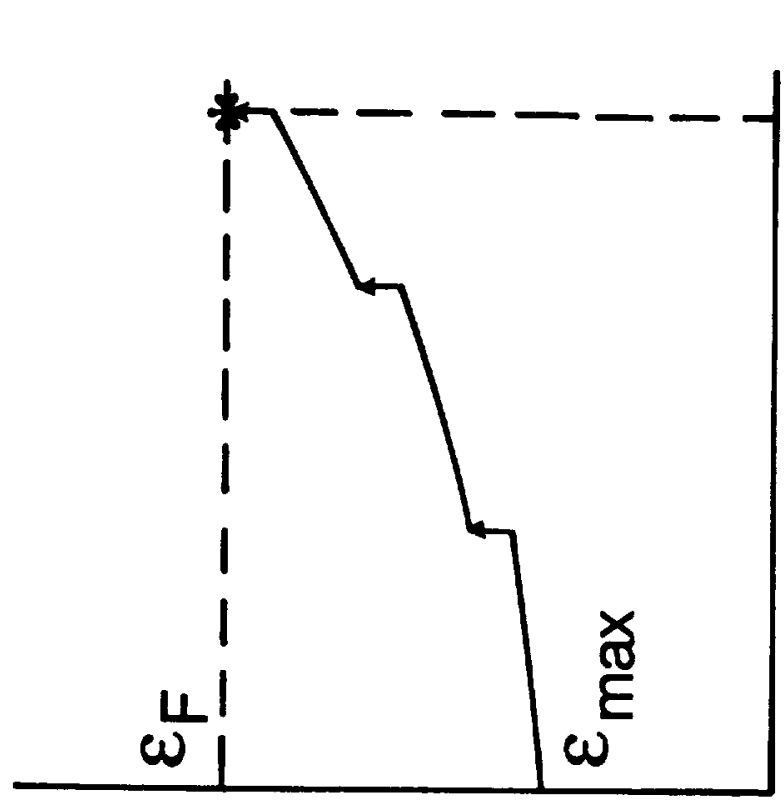

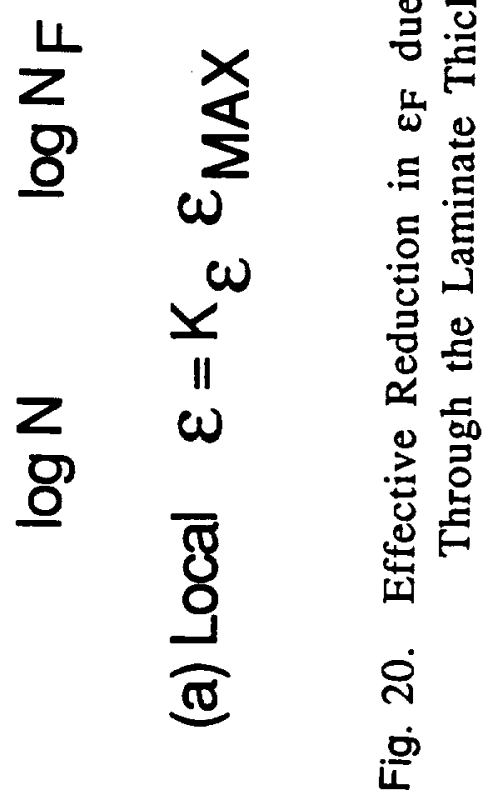

$\bar{g} \omega$ 


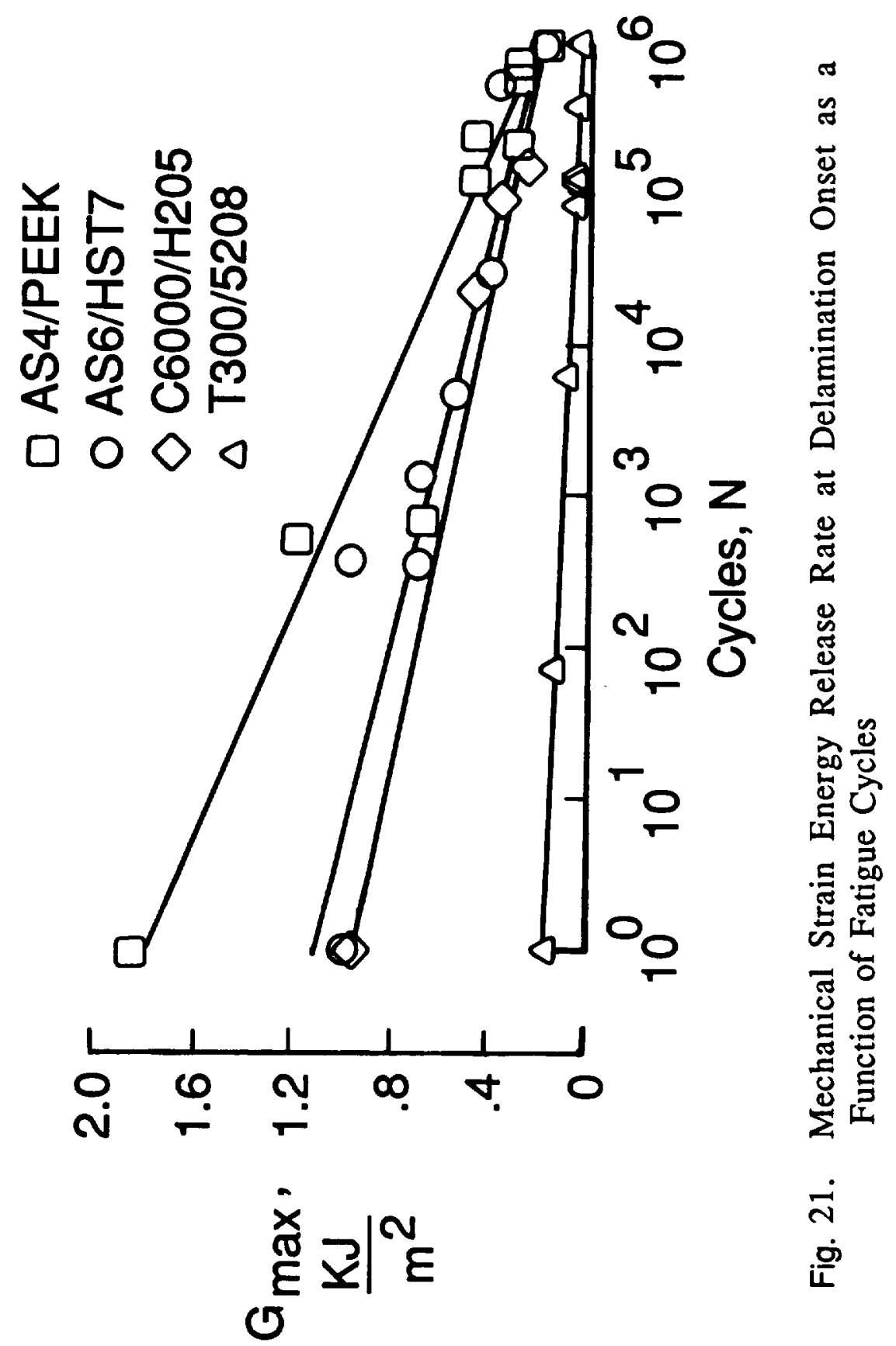




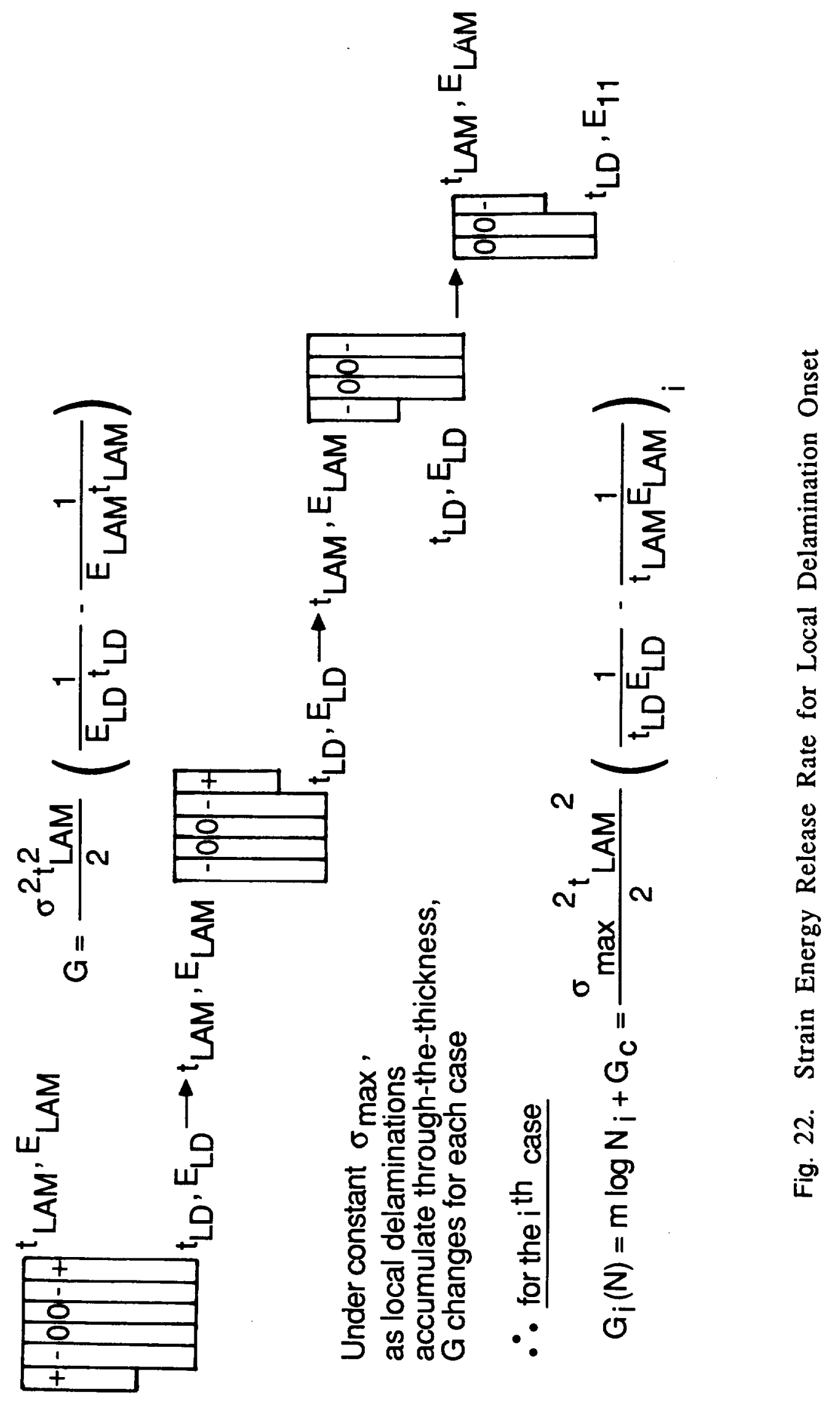




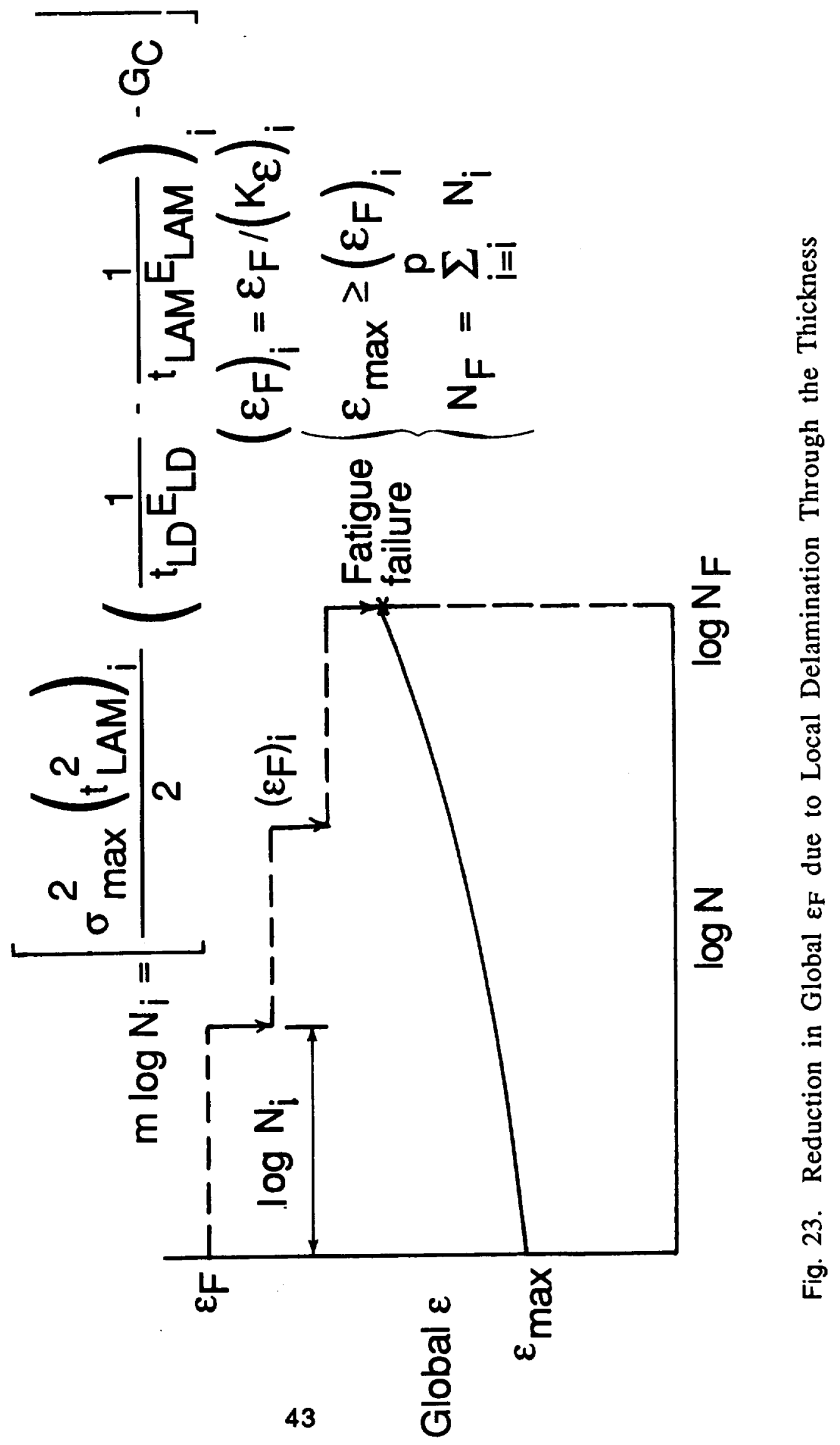




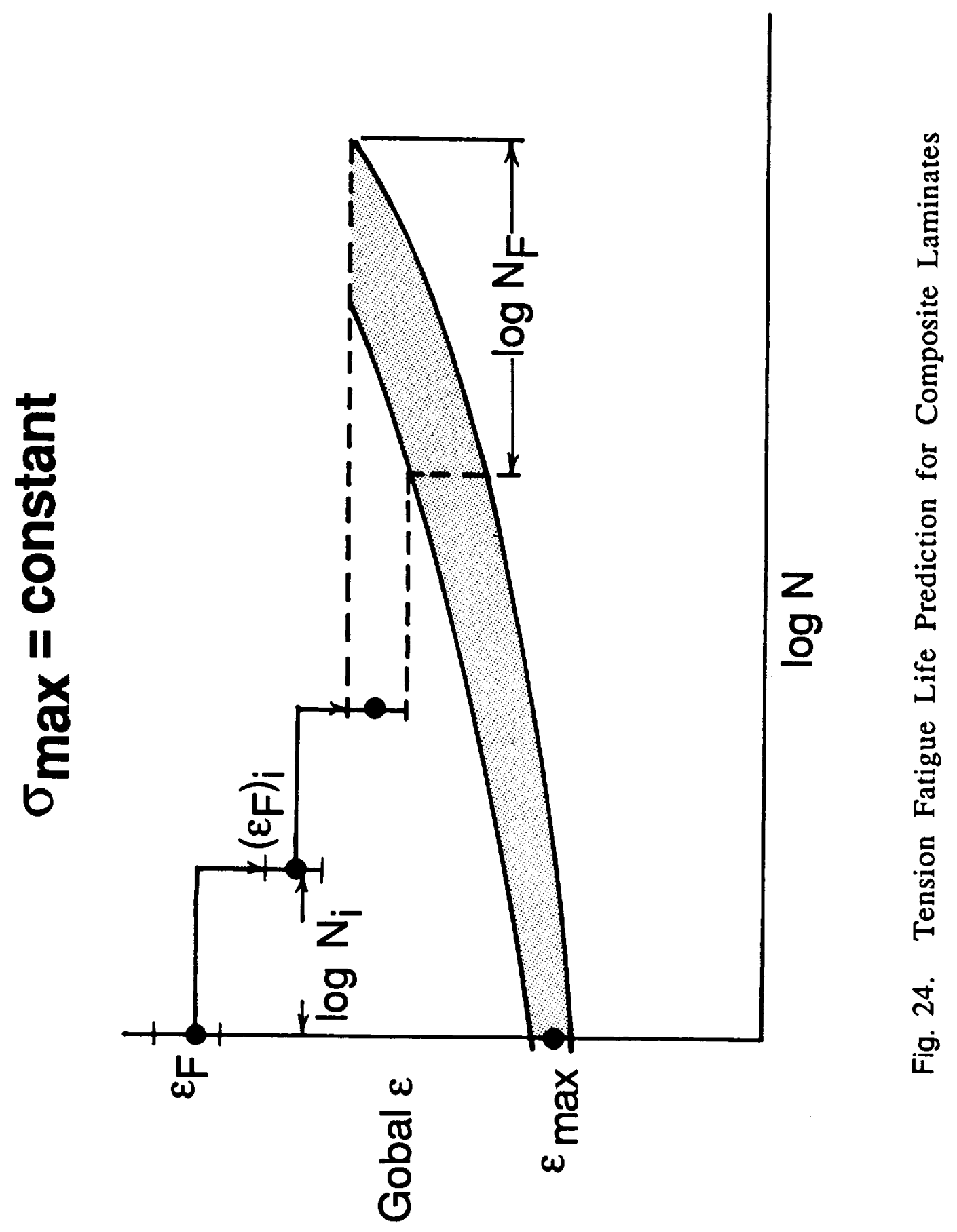




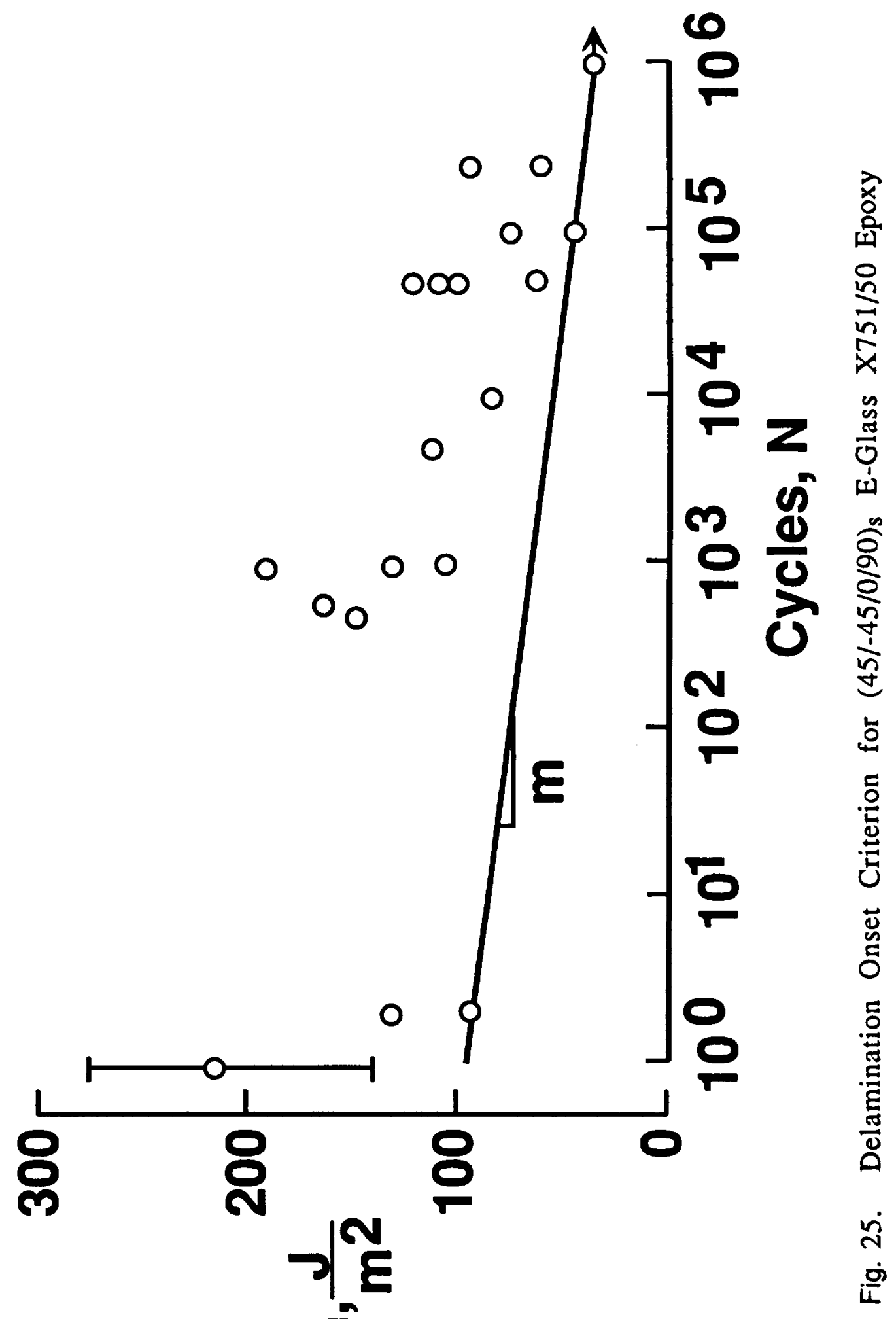

ज์ 


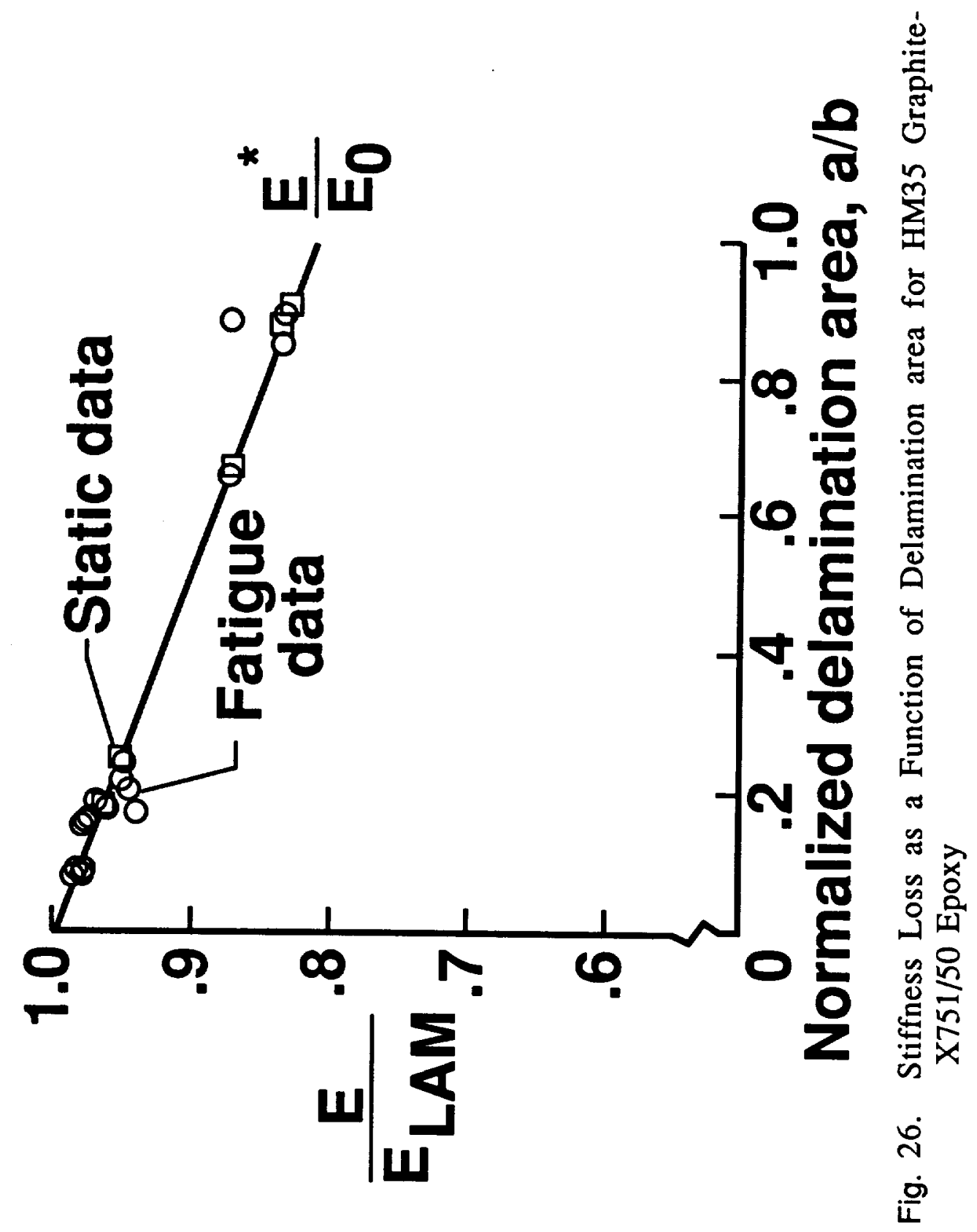




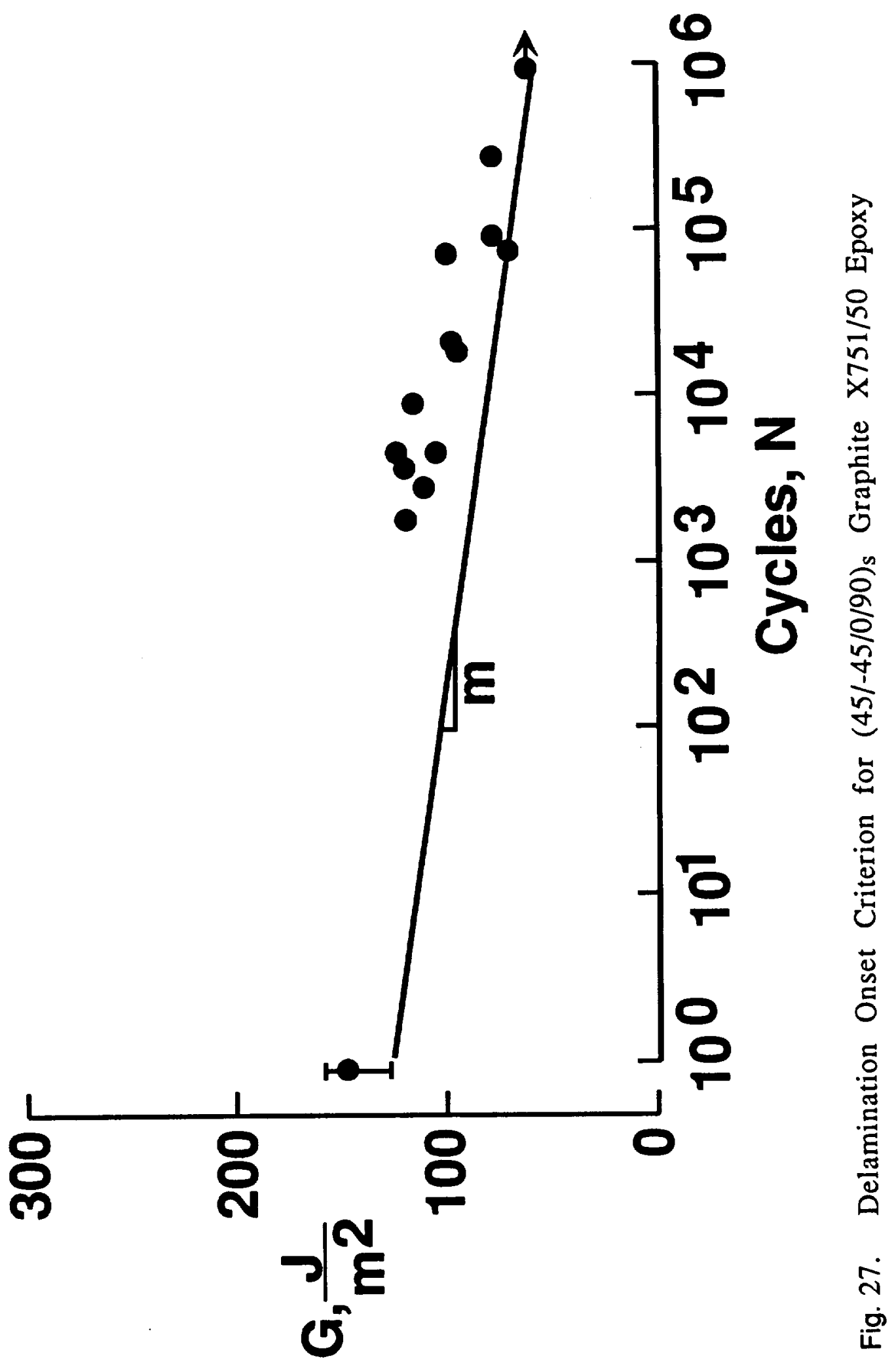




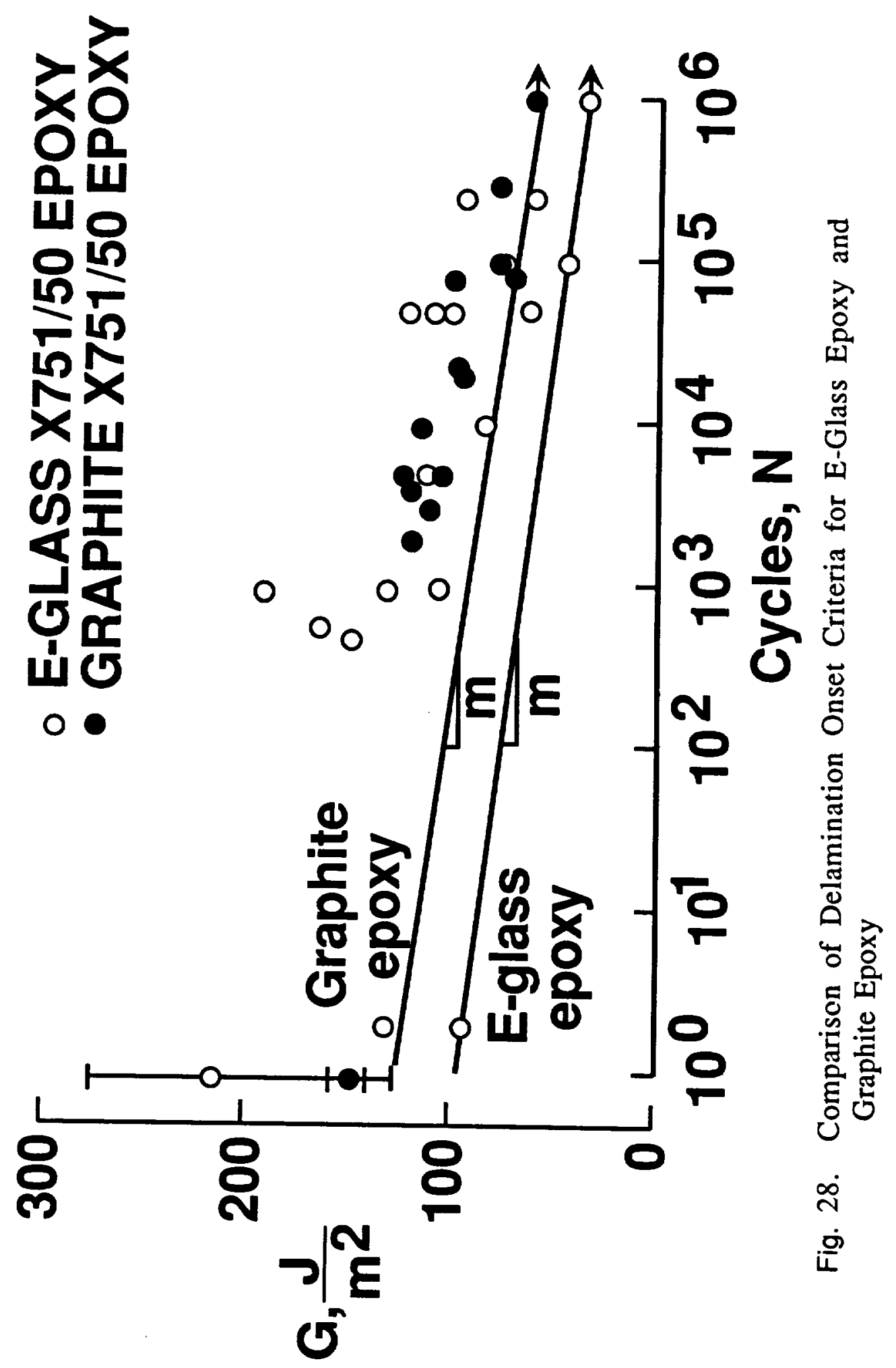




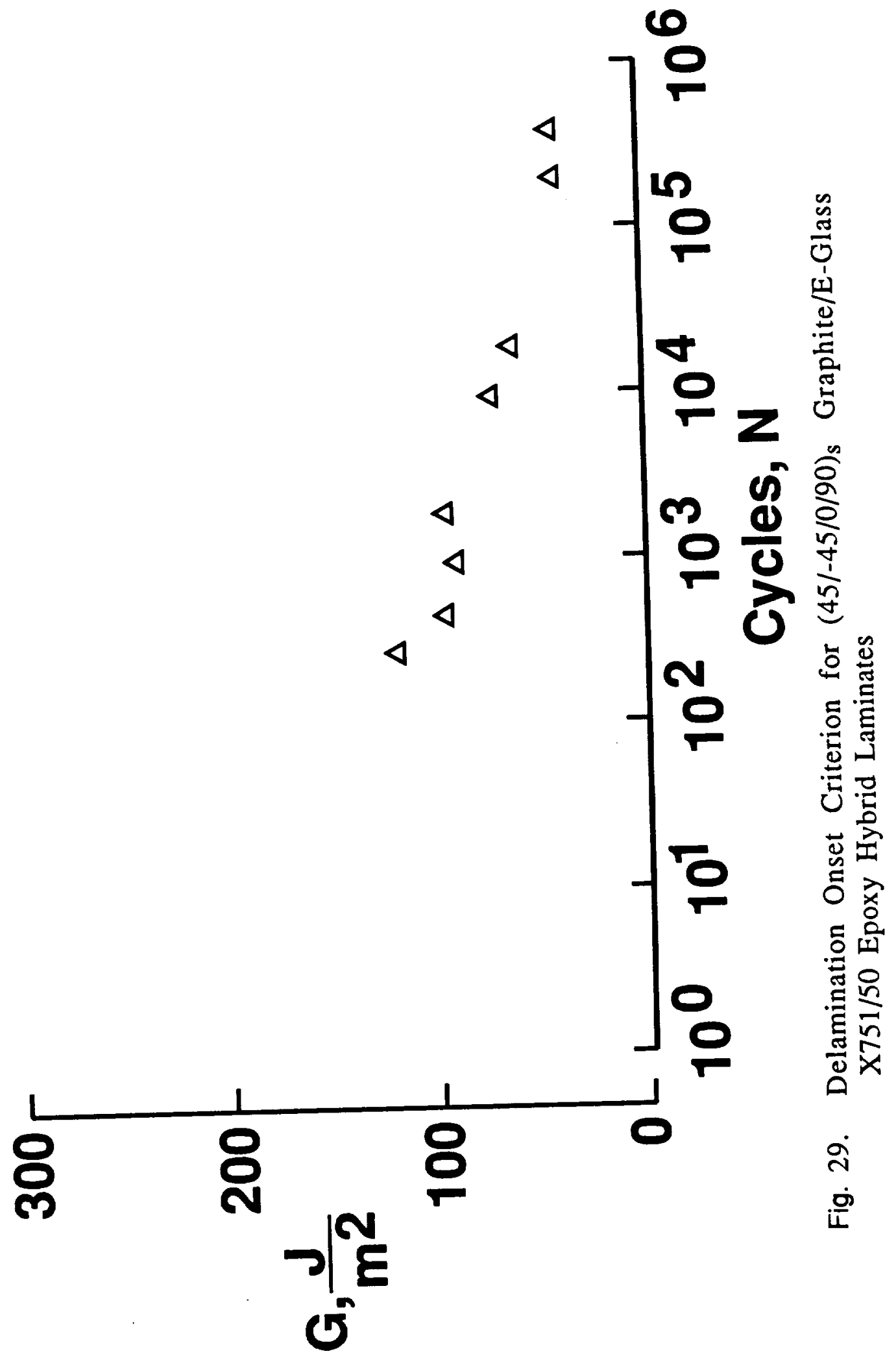




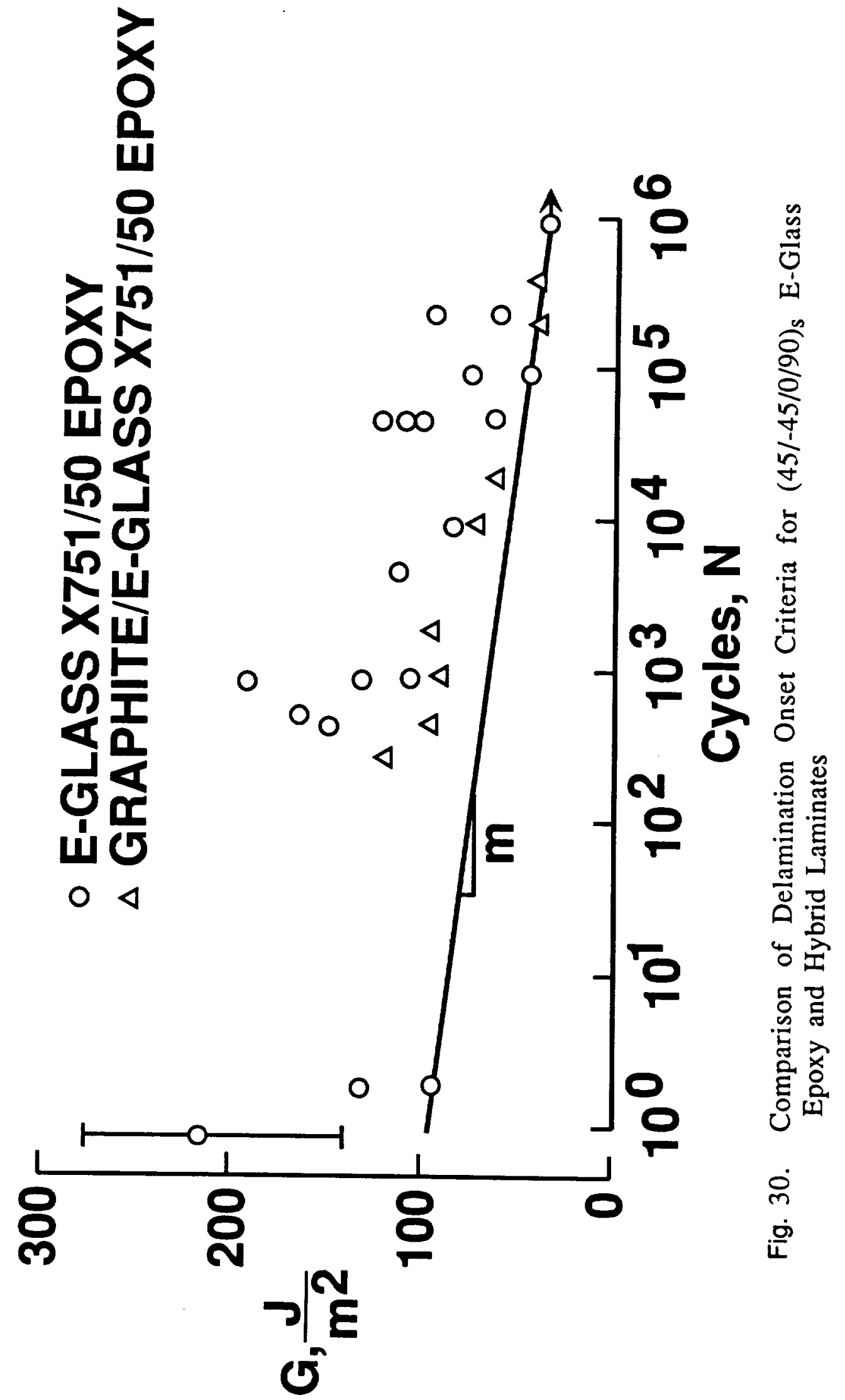




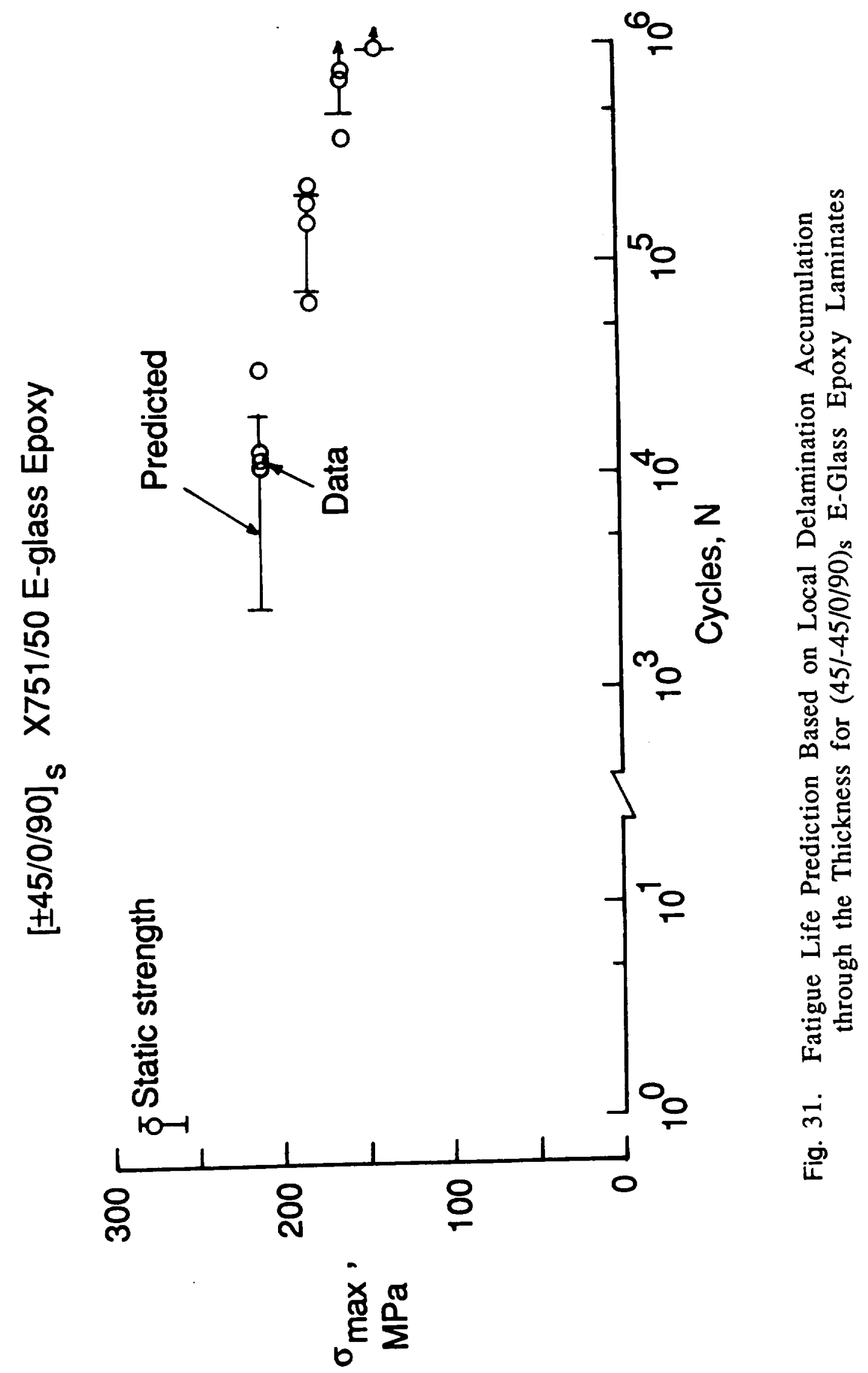




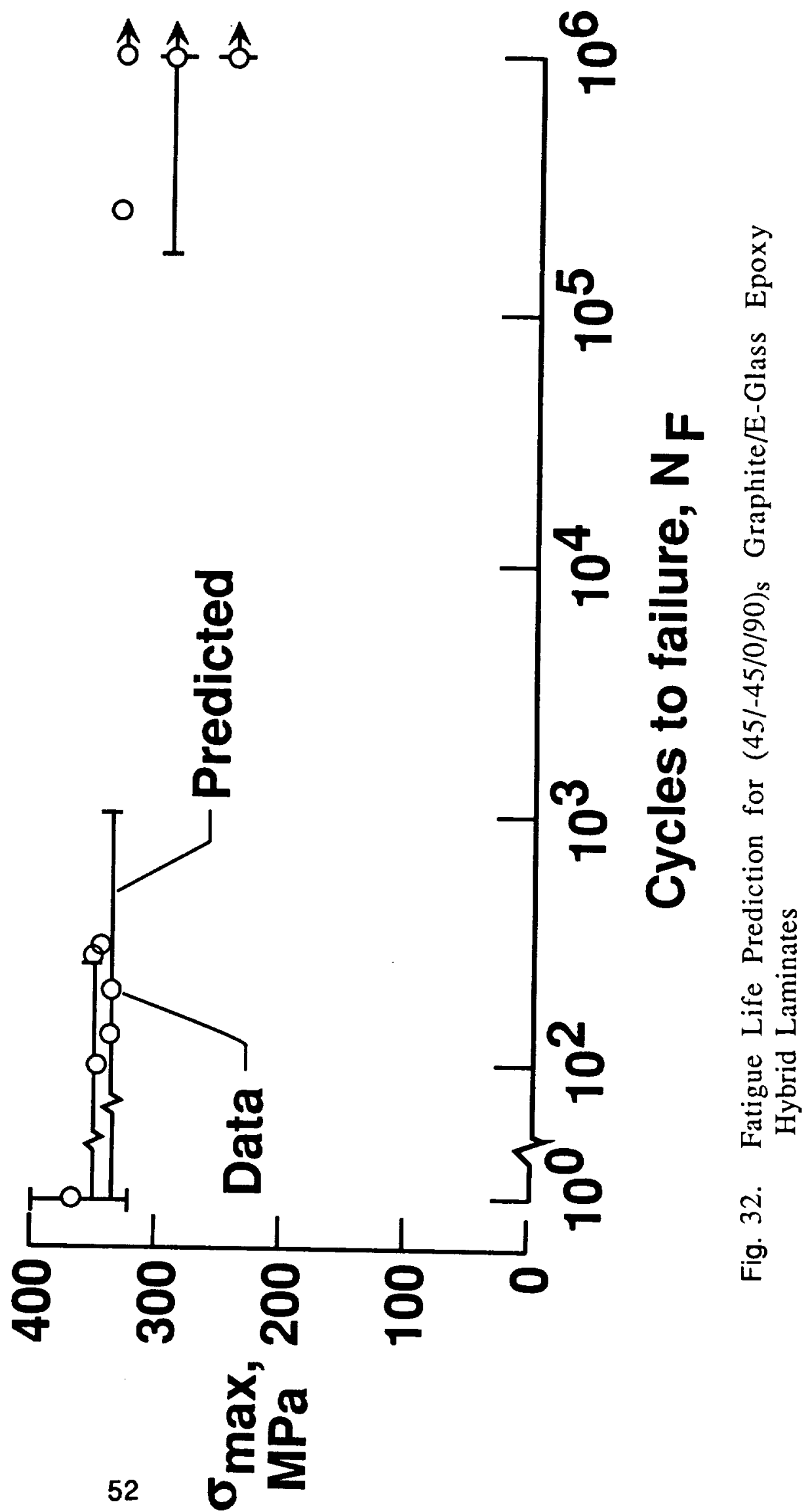




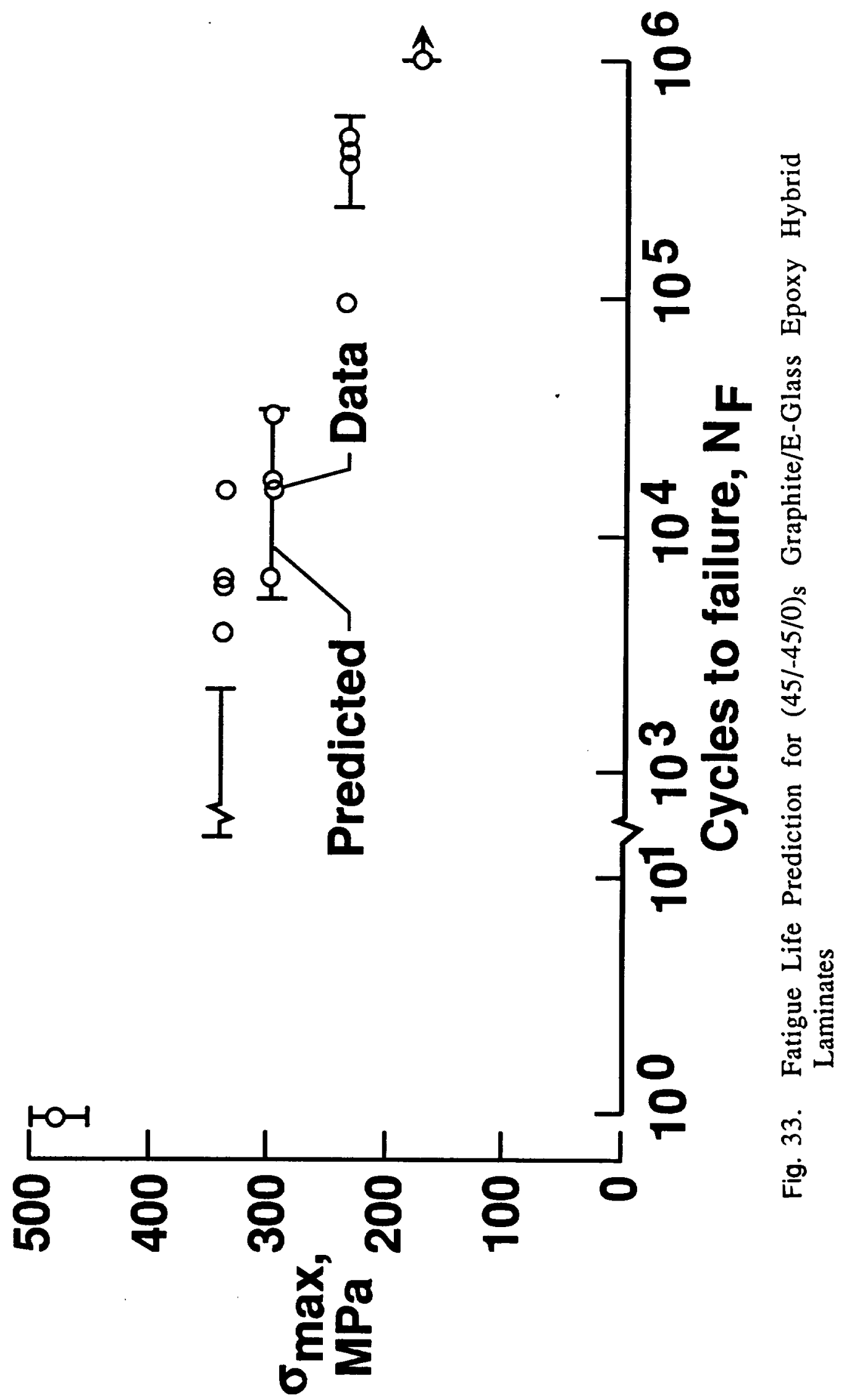




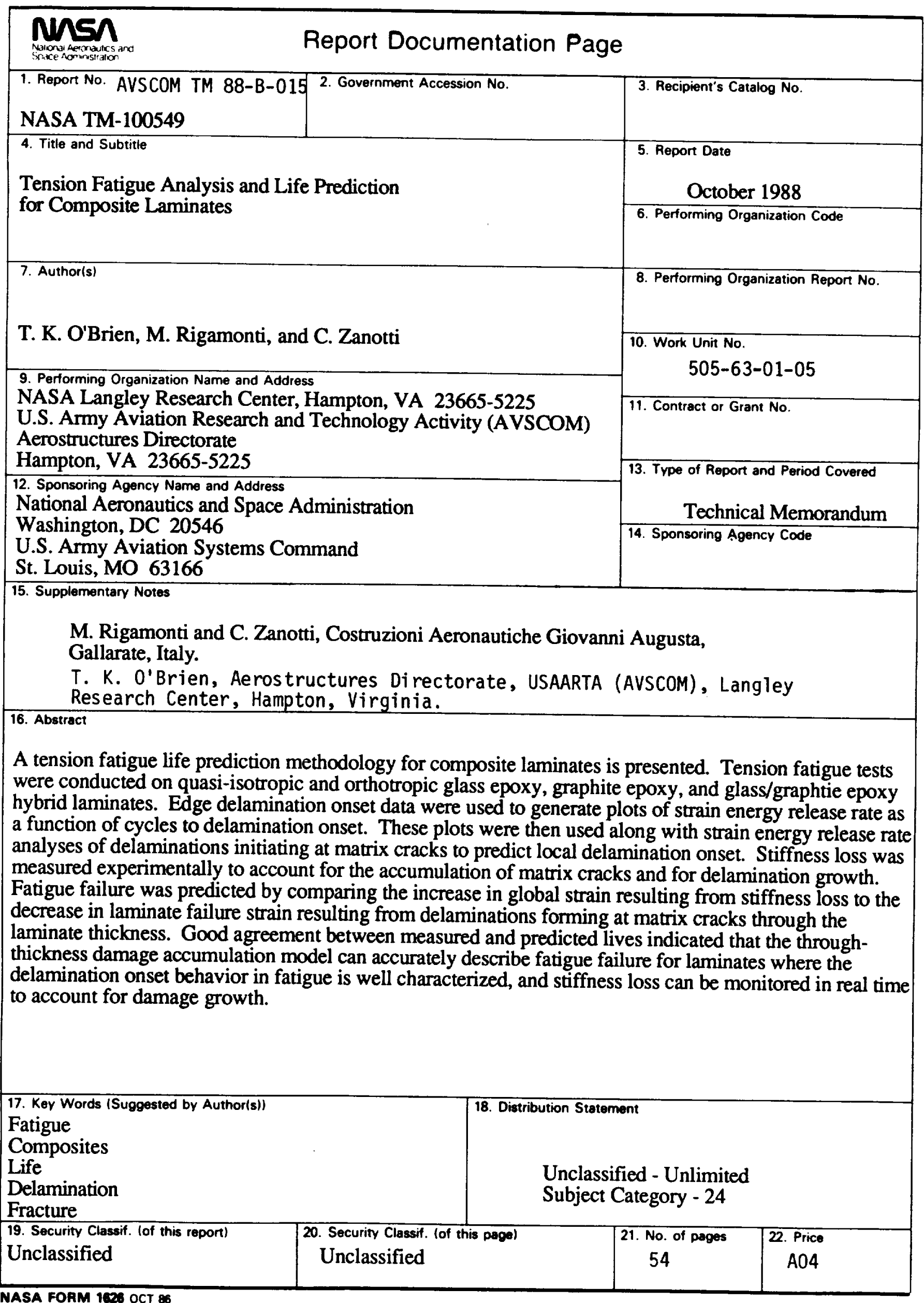

